\title{
LOS PRIORATOS DE SANTA MARÍA DE OIA EN EL SUDOESTE GALLEGO Y EN EL NOROESTE PORTUGUÉS A FINES DE LA EDAD MODERNA: APROXIMACIÓN A SU SITUACIÓN ECONÓMICA*
}

\author{
POR \\ MARÍA SEIJAS MONTERO \\ Universidad de Vigo \\ mariaseijas@uvigo.es
}

\section{RESUMEN}

En este artículo se estudia la situación económica de tres prioratos dependientes del monasterio cisterciense de Santa María de Oia, a través del análisis de dos aspectos fundamentales. En primer lugar, se analiza la estructura y evolución de los ingresos para conocer las cantidades de productos en especie o de dinero que anualmente declaraban las instituciones. El objetivo fundamental es demostrar como la administración descentralizada a través de los prioratos fue clave para hacer frente al mantenimiento de la vida en comunidad y, por consiguiente, imprescindible para afrontar los gastos de la casa central. En segundo lugar, se estudia la distribución y evolución del gasto para poder averiguar el dinero que finalmente era enviado a la casa central.

PALABRAS CLAVE: Galicia; Portugal; cistercienses; prioratos; ingresos; gastos

\section{THE PRIORIES OF SANTA MARÍA DE OIA IN THE SOUTHWEST OF GALICIA AND IN THE NORTHWEST OF PORTUGAL AT THE END OF THE MODERN AGE: APPROACH TO THEIR ECONOMIC SITUATION}

\begin{abstract}
In this we study the economic situation of three priories dependent of the cistercian monastery of Santa María de Oia, through the analysis of two fundamental aspects. First, analyze the structure and evolution of income for quantities of products in kind or money that annually declared institutions. The main objective is to demonstrate how the administration decentralized through the priories was key to deal with the maintenance of life in community, and therefore essential to meet the expenses of the central house. Secondly, will examine the distribution and evolution of the expenditure to be able to find out the money that was finally sent to the central house.
\end{abstract}

KEY WORDS: Galicia; Portugal; cistercians; priories; income; expenses.

Recibido/Received 14-08-2013

En la actual provincial de Pontevedra se situaban en la Edad Moderna cuatro monasterios masculinos cistercienses: Aciveiro, Armenteira, A Franqueira y Oia. ${ }^{1}$ El origen

* Trabajo realizado en el marco del proyecto de investigación "Religiosidad y Reforma católica en el Noroeste de la Península Ibérica durante el Antiguo Régimen" (HAR2013-44187-P), financiado por el Ministerio de Economía y Competitividad.

1 El estudio de estos monasterios en la Edad Moderna ha sido abordado por Seijas Montero, M. 2010. Los monasterios cistercienses en el sudoeste gallego a fines del Antiguo Régimen. Santiago de Compostela: Universidade de Santiago. Véase mapa 1. del patrimonio de estas abadías se remonta a su constitución y tiene las características propias de los monasterios medievales. Las vías de acceso a la propiedad por parte de los monjes estaban caracterizadas por las donaciones reales y particulares de los momentos fundacionales y por las diferentes cesiones que recibirían en los siglos siguientes. El trabajo realizado por E. Portela y $\mathrm{M}^{a} \mathrm{C}$. Pallares demuestra que el monasterio de Oia -casa matriz de los prioratos aquí estudiados- tuvo en las compras, con un porcentaje del 74,6 por ciento $-68,9$ teniendo en 
cuenta los cambios $-{ }^{2}$ la modalidad mayoritaria de adquisición del patrimonio monacal en los siglos XII y XIII. Unas compras que fueron más importantes a partir de los años treinta del XIII, coincidiendo con la disminución de las donaciones. Esto permitió a la comunidad escoger dónde adquirir sus bienes, pues ahora no dependían de unas donaciones situadas en espacios geográficos en los que los monjes no tenían una participación activa a la hora de su elección. Así, la formación del monasterio de Oia tuvo hasta el siglo XIV dos etapas bien diferenciadas: una, en la que la forma jurídica de la donación -real casi en exclusividad hasta 1160, y particular desde ese momento- fue el principal mecanismo adquisitivo de bienes hasta los últimos veinte años del siglo XII; otra, a partir de 1180, en la que las compras a particulares se convirtieron en la modalidad preferida por los monjes para acrecentar sus posesiones no solo en Galicia, sino también en el territorio portugués. Existe, por lo tanto, una clara evolución del dominio de Santa María de Oia desde sus inicios en 1130, ya que si es cierto que las donaciones fueron la columna de apoyo sobre la que se asentó el posterior desarrollo del dominio, las compras, desempeñaron un papel destacado para el crecimiento del patrimonio, por lo menos, hasta principios del XIV. ${ }^{3}$ Con la llegada del siglo XV el monasterio prácticamente consolidó un dominio que se encargó de mantener a lo largo de la Edad Moderna tanto en la zona costera -área más próxima al cenobio- como en la de montaña y valles interiores. ${ }^{4}$

Los cenobios del sudoeste pontevedrés no fueron ajenos a las formas de explotación directa -aplicada, sobre todo, a los bienes próximos a las comunidades, en los que la explotación estaba asegurada gracias a un conjunto de criados o sirvientes que solían establecerse en las cercanías de los monasterios- e indirecta de la propiedad que era la más habitual debido a la dispersión de los bienes. ${ }^{5}$ Una

2 Pallares y Portela cifran en 21 los cambios realizados por el monasterio de Oia entre 1130 y 1305 con el objeto seguramente de conseguir territorios más cercanos al monasterio a costa de perder otros más alejados. Pallares Méndez, Ma del C. y Portela Silva, E. 1971. El bajo Valle del Miño en los siglos XII y XIII. Economía agraria y estructura social: 79-80 Santiago de Compostela: Universidade de Santiago.

3 E. Portela ha demostrado hace algunos años que el monasterio de Oia inicia con el siglo XIV "el cambio de trayectoria en la curva de sus adquisiciones. Si desde 1160 el volumen de sus adquisiciones no había dejado de acrecentarse, entre 1300 y 1400 desciende continuamente y a grandes pasos" en Portela Silva, E. 1976. La región del obispado de Tuy en los siglos XII a XV: una sociedad en la expansión y en la crisis: 294 Santiago de Compostela: El Eco Franciscano.

4 En el siglo xv el monasterio de Oia "continúa el proceso de concentración en tres zonas fundamentales: A Guarda, donde se producen seis cambios; la zona de Loureza-Burgueira, con tres; y en tercer y último lugar, el valle de O Rosal", cfr. en Sánchez Carrera, Mạ del C. 1997. El Bajo Miño en el siglo XV. El espacio y los hombres: 134-135 A Coruña: Fundación Pedro Barrié de la Maza.

5 A este respecto el Tumbo del monasterio de Oia se refiere a los cuarenta criados donados que tuvo el convento que cultivaron y poblaron la tierra cercana al monasterio, en la feligresía de San Mamede de Pedornes, con los que: "se fueron ronpiendo en este monte ynculto y despoblado algunos pedazos que parecían de la mejor tierra y haciendo algunas heredades de pan llebar; zerrandolas de paredes por caussa de los ganados; y como fuese creciendo el número de la xente el convento fue aforando a algunos de los mesmos criados algunas heredades de las que se havían rompido y haciendo algunas cassas para que vibiesen de que se origino el formarse los lugares y aldeas que al presente hay en esta feligresía y que por la procreaçión de la xente se han ydo aumentando modalidad contractual que llevaba a los monjes a ceder el dominio útil a cambio de una pensión anual, mediante los foros y los arriendos, aunque estos últimos fueron minoritarios, no solo en Galicia, sino también en otras zonas del norte como la asturiana. La principal área de influencia de los dominios de las abadías se extendía por la actual provincia de Pontevedra y, en menor medida, por las de A Coruña y Ourense. ${ }^{6}$ Un dominio monástico tan amplio exigía una buena racionalización de la administración, de lo contrario, el oscurecimiento de las propiedades iría deteriorando sus rentas, como ya había ocurrido en los siglos bajos medievales. Las comunidades repartían el control de su dominio a través de los propios monasterios, que controlaban sus áreas más próximas, y de los prioratos que se encargarían de las zonas más alejadas. Regidas por un prior, designado por el abad que los visitaba dos o tres veces durante su mandato, estas casas estaban facultadas para llevar una contabilidad independiente de la que debían dar cuenta al abad en sus visitas. Precisamente, fue el crecimiento de los dominios monásticos el causante de un sistema de organización centralizada, en el que estas filiales supervisaban la explotación de las propiedades de las abadías, recaudando sus rentas y llevándolas a la casa central, donde se registraban las contabilidades de las comunidades. Como era habitual en este tipo de instituciones, una vez que los priores percibían las rentas -y luego de hacer frente a su mantenimiento, la casa en la que vivían y su servicio doméstico- vendían el producto y este pasaba a la contabilidad en dinero. Así, los prioratos actuaban como enclaves fundamentales para la percepción de las rentas y la vigilancia de los patrimonios monásticos, pero también como centros de comercialización en los que vendían el cereal, el vino y los otros productos que no se enviaban a la casa central para su consumo. Además, los monjes-priores ejercían como párrocos de los lugares en los que estaban enclavados los prioratos por lo que tenían gran influencia sobre las parroquias, mediante el culto, la predicación y el cuidado de las iglesias. ${ }^{7}$

y por dicha razón cultibando las demas tierras aunque todavía hay mucho de monte y por ronper que sirbe de tomadas zercadas para pastos de los ganados y de que sacan los foreros del Monasterio mucha utilidad de la leña de toxo que benden para fuera". AHN, Códices, Li. 60 , fol. $26 \mathrm{v}$. El predominio de la explotación indirecta en Galicia permite hablar de un modelo propio, frente a la importancia que para las economías monásticas castellanas tenía la explotación directa de su dominio. Véase, entre otros, García Martín, P. 1985. El Monasterio de San Benito el Real de Sahagún en la época moderna Valladolid: Junta de Castilla y León; López García, J. M. 1982. “Economía monástica y sociedad rural en Valladolid durante el Antiguo Régimen La Real Cartuja de Nuestra Señora de Aniago", Annales de la Universidad de Alicante 2: 83-134 y López García, J. M. 1990. La transición del feudalismo al capitalismo en un señorío monástico castellano: el Abadengo de la Santa Espina (11471835) Valladolid: Junta de Castilla y León; Sebastián Amarilla, J. A. 1992. Agricultura y rentas monásticas en tierras de León. Santa María de Sandoval (1167-1835) Madrid: Universidad Complutense; para el caso extremeño es indispensable la obra de Llopis Agelán, E. 1980. Las economías monásticas al final del Antiguo Régimen en Extremadura Madrid: Universidad Complutense.

6 La localización del dominio de los monasterios del sudoeste gallego puede verse en los mapas publicados en el artículo de Seijas Montero, M. 2012. "El patrimonio de los monasterios cistercienses del sudoeste gallego en la Edad Moderna". Hispania 241: 423-452.

7 Rey Castelao, O. 2002. "El clero regular de la diócesis compostelana en la Época Moderna”, en J. García Oro (coord.), Historia de las 
No se tiene noticia de la existencia de ningún priorato en Santa María de A Franqueira -este no era propiamente un monasterio sino una presidencia, unido al colegio de Salamanca, desde su incorporación a la congregación en 1521- pero sí en los de Aciveiro, Armenteira y Oia. ${ }^{8}$ El primero contaba con dos en la actual provincia de Ourense, el vinatero de Banga y el cerealero de Beariz, que eran los encargados de la recaudación de las rentas en aquellas parroquias de la provincia orensana en las que el monasterio tenía bienes. Además, el sistema de recaudación de los prioratos se realizaba conjuntamente con las paneras que el monasterio tenía repartidas en diferentes lugares. Dependientes de Santa María de Armenteira había cinco prioratos distribuidos por las jurisdicciones de Caldebergazo, Lanzada y Val de Fragoso, lo que aseguraba al monasterio la administración de las haciendas monásticas situadas en aquellas zonas más alejadas de la casa central. Finalmente, Oia contaba con tres prioratos en Galicia -Panxón, Goián y O Rosal-y uno en el vecino reino de Portugal, Silva, que reunía todas las posesiones del noroeste portugués.

Los monasterios del císter, por lo tanto, dieron origen a una nueva forma de organizar y explotar sus propiedades a través de unas filiales que se configuraban como unidades con relativa autonomía, encargadas de la administración de una parte del patrimonio monacal, pero dependientes a su vez de las casas centrales a las que transferían sus excedentes después de satisfacer sus necesidades de autoconsumo. Sin embargo, el desmantelamiento de los prioratos a fines del XVIII supuso poner en cuestión todo el sistema.

Precisamente, en este artículo se aborda el estudio de tres prioratos dependientes de Santa María de Oia: Panxón, O Rosal y Silva. El objetivo es reconstruir sus contabilidades para dejar constancia de que, aunque oficialmente era el abad del monasterio el que tomaba las decisiones, como centralizador de la actividad monástica, fueron los priores los que dirigieron la gestión de los prioratos, no solo realizando foros y apeos o resolviendo conflictos, sino también rindiendo cuentas anuales de los ingresos y gastos ante el abad de Oia. Las fuentes consultadas para obtener los datos que se han analizado proceden principalmente de la sección clero del Archivo Histórico Nacional en donde se conserva la mayor parte de la documentación monástica, tras los movimientos desamortizadores del siglo XIX y la supresión de estas instituciones. Se han consultado los libros de cuentas de los tres prioratos de los que se conserva documentación contable. La información que aportan sirve para conocer la composición del recibo y del gasto en especie, indicando los distintos tipos de cereal y vino que declaraba cada una de las casas, además de lo ingresado y gastado en metálico en cada año contable, que comprendía el período entre el quince de abril y la misma fecha del año siguiente. Gracias a ellos también se pueden conocer los canales de entrada de las rentas agrarias y las partidas de gastos que debían afrontar. Finalmente, la confrontación de ingresos y gastos de los prioratos revela el útil o remanente enviado a la casa central.

diócesis españolas: Santiago, Tuy-Vigo: 383-384. Madrid: Biblioteca de Autores Cristianos.

8 Véase mapa 2.

\section{LOS PRIORATOS DE SANTA MARÍA DE OIA}

Desde fines del siglo XIV surgieron dentro de las diferentes órdenes religiosas movimientos de reforma que tenían como objetivo volver al cumplimiento de sus reglas fundacionales caídas en desuso. A dichos movimientos se les denomina de la observancia. En el caso de los cistercienses, la integración en la congregación de Castilla, surgida en los años veinte del siglo XV, no supuso por sí sola un cambio radical de las comunidades, pero marcó el inicio de la modernización pues significó un cambio en el rumbo y estilo de vida de los monasterios luego del ocaso generalizado de los siglos finales de la Edad Media. La observancia cisterciense había llegado a Galicia en el reinado de los Reyes Católicos, interesados en erradicar las costumbres libertinas de los religiosos y mejorar la administración de las casas, pero el gran impulso de reforma monástica y de incorporación de los monasterios pertenece al período de Carlos I. Es cierto, sin embargo, que durante el reinado de Fernando e Isabel fueron varios los monasterios que abrazaron la reforma, entre ellos, el de Aciveiro que quedó unido con sus rentas al colegio de San Salvador de Salamanca en 1505. Con Carlos I se incorporó a la reforma el de A Franqueira en 1521, unido también al colegio salmantino. Dos años después conseguía la unión definitiva Santa María de Armenteira y en 1547 la abadía tudense de Santa María de Oia, poniendo fin al largo proceso de reforma de las órdenes monásticas en Galicia. ${ }^{9}$

La reforma que conllevó la adscripción condujo en la mayoría de los casos -los pequeños monasterios se concentraron o pasaron a depender como prioratos de otros más importantes- a un nuevo periodo de auge económico, a la restauración de la observancia de la regla primitiva y a la intensificación de su vida cultural. En este sentido, el monasterio de Santa María de Oia, situado en el litoral marítimo, a medio camino entre las villas de A Guarda y Baiona, se convirtió, siguiendo un inventario de 1835 , en cabeza o casa madre de tres prioratos en el sudoeste gallego y otro en el vecino reino de Portugal. ${ }^{10}$ En primer lugar, San Xoán de Panxón, situado en la jurisdicción del mismo nombre, en una feligresía habitada en 1753 por 210 vecinos, $^{11}$ no fue un enclave casual para un priorato. Era un puerto de mar utilizado para la pesca -como parte importante en la dieta alimenticia de los monjes-, pero quizás también para el comercio, el transporte de mercancías, compradas o vendidas, e incluso el comercio de pescado. ${ }^{12}$ De hecho, a mediados del XVIII había en esta

9 Yáñez Neira, D. 1991. “Los monasterios cistercienses gallegos en la reforma de fray Martín de Vargas", en J. C. Valle Pérez (ed.), El monacato en Galicia durante la Edad Media: la orden del císter: 71-106. Santiago de Compostela: Fundación Alfredo Brañas; Fernández Cortizo, C. J. 2000. "Las reformas de las Órdenes de San Benito y del Cister en Galicia en tiempos de Carlos V", en A. Eiras Roel (coord.), El reino de Galicia en la época del emperador Carlos V: 847-877. Santiago de Compostela: Xunta de Galicia; García Oro, J. y Portela Silva, Mã J. 2002. "El císter gallego en el reinado de Carlos V", en Aproximaciones al reinado de Carlos V: 9-43. A Coruña: Fundación Caixa Galicia.

10 AHPP, Inventarios de bienes monásticos, G-8366 (Carp. 10-2).

11 AGS, Catastro de la Ensenada, leg. 271, fol. 208.

12 Cendón Fernández, M. 2000. "Santa María de Oia”, en D. Yánez Neira (coord.), Monasticón Cisterciense Gallego V. 1: 203. León: Caixa Vigo e Ourense. Hay varios ejemplos sobre la importancia del pescado en la dieta de los monjes bernardos. A. Meijide hace referencia al consumo de bacalao en varios conventos, colegios y hospicios de Galicia en 1752, Oia consumiría una media de 30 arrobas anuales de este 
feligresía diez embarcaciones "de pescar sardina en la ría, a las que vulgarmente llamaban dornas (...) cuia pesca hazían ordinariamente desde primero de julio asta fin de nobiembre de cada un año". ${ }^{13}$ Este priorato tenía encomendada la misión de administrar las propiedades situadas en veintiuna feligresías, próximas a la casa central, pero también alejadas de ella. ${ }^{14}$ Por su parte, la casa prioral de San Lourenzo de Goián estaba situada en el coto del mismo nombre, en el que vivían 25 vecinos en 1753, y en donde había "una barca de pasage, que conducía gente en el río Miño desde este coto a la Villa Nueva de Zervera del reino de Portugal, cuia barca era de la cámara de Portugal". ${ }^{15}$ La pesca de río, con toda seguridad también aprovechada por los monjes de Oia, se llevaba a cabo en esta feligresía con dos barcos pequeños que eran los encargados de pescar en el Miño salmones, sábalos y lampreas. ${ }^{16}$ En la jurisdicción de A Guarda se encontraba el priorato de O Rosal, en la feligresía homónima, cuya vecindad era en 1753 de 966 efectivos, lo que la convertía en una de las mayores del obispado de Tui. Dada su cercanía a la sede central sería el encargado de ayudarla en la administración de los bienes que el cenobio tenía en esta zona. En cuanto al priorato o granja de Santa María da Silva, estaba localizado en el "termo da villa de Valença de Minho", ${ }^{17}$ en el distrito de Viana do Castelo, región norte y subregión de Minho-Lima. El priorato, favorecido por los privilegios reales de los monarcas de España y Portugal, que le permitieron pasar de uno a otro reino sus frutos sin satisfacer derechos de tránsito, ${ }^{18}$ era

producto, las mismas que el monasterio de Armenteira según los datos del documento de Rentas. Aduanas, leg. 510, doc. 23 feb. 1752, AGS, cfr. en Meijide Pardo, A. 1980. El comercio del bacalao en la Galicia del siglo XVIII: 70-73. La Coruña: Diputación Provincial; Vázquez Lijó, J. M., Y Sandoval Verea, F. M. 2009. "Alimento de vigilias: el pescado en la dieta de los cistercienses gallegos a finales del Antiguo Régimen", en R. Casal, J. M. Andrade y R. López (eds.), Galicia monástica: estudos en lembranza da profesora María José Portela Silva: 333-359. Santiago de Compostela: Universidad de Santiago y Vázquez Lijó, J. M. 2009. "Sabrosa abstinencia: abasto y consumo de pescado en el monasterio de Sobrado (ss. XVIIXVIII)". Obradoiro de Historia Moderna 18: 151-179.

13 AGS, Catastro de la Ensenada, leg. 271, fol. 214.

14 La distribución de los bienes se reparten por las siguientes feligresías: San Lourenzo de Belesar, Santa Cristina de Ramallosa, Santa María de Baiona, Santa Mariña de Baíña, Santa María de Baredo, Santiago de Cangas, San Martiño de Borreiros, San Miguel de Peitieiros, San Vicente de Mañufe, Santa María de Chaín, Santa María de Vilaza, Santiago de Morgadáns, San Bieito de Gondomar, Santa María de Vincios, San Fiz de Nigrán, San Pedro de A Ramallosa, Santa Baia de Camos, Santiago de Parada, San Xoán de Panxón, San Miguel de Oia y San Pedro de Sárdoma. AHPP, Inventarios de bienes monásticos, G-8366 (Carp. 11). Seijas Montero, M. 2012: 434.

15 AGS, Catastro de la Ensenada, leg. 270, fol. 60.

16 Ibídem, fol. 62.

17 AHN, Códices, Li. 1.037, fol. 2r.

18 A pesar de los derechos que tenía el monasterio para la libre circulación de mercancías, existieron conflictos por este motivo como ocurre en el año 1697 que "aviendo ympedido el passar algunas cosas de la Granja de la Silva de Portugal, D. Antonio de Araujo, administrador en Tuy, y D. Francisco de Lossada y D. Francisco Ozores, su yerno, acudió el Monasterio al Señor Capitán General el qual mandó que guarden y cumplan los privilegios para que dicho convento pueda sacar de Portugal treinta pipas de vino, que cada una hace veinticinco arrobas, ochenta arrobas de aceyte, doce arrobas de azúcar, seis de confituras y conservas, veynte resmas de papel, treynta docenas de platos y escudillas, jarras y otras cosas de Talavera, diez y seis fanegas de sal de pala cargada para que tiene cedula especial de su Magestad, pimienta, clabo y otras cosas constando por certificaçión jurada del prelado que son para el gasto de dicho monasterio y no para otra persona alguna y al tiempo que el encargado de explotar y administrar algunos de los bienes que el monasterio tenía en el reino portugués: "muitos casares e erdades nos termos e comcelhos de Valença de Minho e no termo de Villanova e Serveira". ${ }^{19}$ El tumbo de 1560/1565, realizado siendo abad del monasterio fray Prudencio de la Fuente, completado con un memorial cobrador del priorato realizado en el siglo $\mathrm{XIX},{ }^{20}$ reflejan que algunas de las adquisiciones de Oia en el reino portugués se concentraron en los municipios de Valença -donde se ubicaba el priorato-, de Vila Nova de Cerveira, situado también en el distrito de Viana do Castelo y limitando al nordeste con el municipio de Valença y al sudoeste con Caminha que es el otro municipio, en el mismo distrito, en el que Oia tenía posesiones, concretamente, en la villa de Caminha. ${ }^{21}$ De esta forma Oia, al igual que los otros cenobios del sudoeste gallego, utilizó sus prioratos como filiales encargadas de supervisar sus explotaciones y de recaudar unas rentas diseminadas que acabarían confluyendo en la sede central.

\section{ESTRUCTURA Y EVOLUCIÓN DE LOS INGRESOS}

La información que ofrecen las contabilidades del monasterio de Oia permiten analizar tres de sus cuatro prioratos, dos de ellos situados en territorio gallego, Panxón y O Rosal, y el otro en el litoral portugués, Santa María da Silva. La composición de los ingresos cerealeros de San Xoán de Panxón, la segunda unidad administrativa más importante de la casa central, sin tener en cuenta Goián, de la que no se tienen datos, demuestra que sus entradas anuales entre 1720-1783 dependían del maíz, que ocupa la primera posición con un porcentaje del $48,3 \%$, seguido del centeno, $31,2 \%$, y del trigo, $20,4 \%$. Además, la renta recibida por la sede prioral no experimentó apenas cambios a lo largo del período (tabla 1) con una media anual de 556 ferrados de maíz (110 hl.), 359 de centeno ( $55 \mathrm{hl}$.) y 235 de trigo ( $36 \mathrm{hl}$.). Esta misma composición se repite en la granja de Silva en el período 1720-1834,

passen dichos generos los registren dichos administradores o sus guardas para que se eviten fraudes. Y que no lleven derechos ningunos ni hagan molestia en la dilaçión de dhos registros con apercivimiento que si faltaren a ello y constare se le sacaran doçientos ducados de multa", AHN, Códices, Li. 60, fol. 10r.

19 AHN, Códices, Li. 1.035, fol. 1v.

20 AHN, Códices, Li. 1.037 y Li. 1.038.

21 Las feligresías en las que se localizan las posesiones de Santa María de Oia en Portugal eran: Cerdal, San Miguel de Fontoura, Santa María da Silva, São Julião, São Pedro da Torre y Valença (en el actual municipio de Valença); Campos, Cornes, Reboreda, Vila Meã, São Pedro de Gondarém, Vila Nova de Cerveira (en el municipio de Vila Nova de Cerveira) y la villa de Caminha (en el municipio del mismo nombre) en Seijas Montero, M. 2010: 183-184. Véase Mapa 3. Las propiedades incluidas en el Tumbo de la granja de Silva también han sido analizadas últimamente por Rodrigues, A. P. 2012. “O tombo de 1560/1565 da granja da Silva do mosteiro de Santa María de Oia. Aspectos da evoluçâo e consolidaçâo do património medieval do mosteiro de Oia no Entre Lima-e-Minho português através da análise de um documento de época moderna". Cuadernos de estudios gallegos 125: 115-142. Según esta autora en el conjunto patrimonial del monasterio de Oia en la Edad Media se incluían no solo estas propiedades del Alto Minho, sino también las localizadas en el término de Torres Vedras, en el actual distrito de Lisboa, que habían sido donadas por el monarca Afonso Henriques al monasterio y confirmadas por Sancho I y Sancho II. Véase Rodrigues, A. P. 2012. "Consideraciones sobre la percepción de frontera. En torno al patrimonio del monasterio de Santa María de Oia en Portugal durante la Edad Media". Historia I+D. Revista de estudios históricos: 9-31. 
siendo también el maíz el que obtuvo el mayor porcentaje, con el $52,5 \%$ del total, el centeno $40,2 \%$ y el trigo el $7,2 \%$. Unos resultados que prácticamente se mantuvieron estables entre 1720 y 1794 con pequeñas variaciones que oscilaron entre el $6-7 \%$ de los ingresos de trigo, $37-40 \%$ de los de centeno y $49-55 \%$ de los de maíz. A partir de aquí hubo un descenso muy acusado de las entradas de centeno y maíz, no tanto de las de trigo, para recuperarse nuevamente a principios del XIX, pero no llegando a superar en ningún momento los valores de mediados de los noventa (tabla 2). Estos resultados ponen de manifiesto, en contraposición con lo que ocurría en la panera monástica, que la aparición del maíz desplazó por completo al mijo, pues no aparece como renta ingresada en ninguno de los dos prioratos durante el siglo XVIII. ${ }^{22}$

La realidad del priorato de O Rosal entre 1765 y 1834 era muy diferente, no en el caso del maíz, que sigue ocupando el primer puesto, sino en los porcentajes que obtienen el centeno y el trigo, y en la presencia en todo el período, de forma destacada, del mijo (tabla 3). Así, durante todo el período las entradas declaradas de cereal estaban compuestas por maíz $(63,1 \%)$, mijo $(14 \%)$, trigo $(11,5 \%)$ y centeno $(11,4 \%)$. Estos porcentajes no se modificaron anualmente en el caso del trigo; la estabilidad también fue la norma para el maíz hasta principios del XIX, cuando su aportación dentro de las rentas totales descendió al 58,2\% para aproximarse al $70 \%$ entre $1810-1829$. Los porcentajes de centeno oscilaron entre el $10-13 \%$ hasta 1804 y descendieron claramente al 8-9\% entre 1805-1829, en el último quinquenio (1830-34) la aportación de este cereal aumentó hasta el 11,1\% en detrimento del maíz que obtuvo el porcentaje más bajo con el $53 \%$. Las oscilaciones más importantes del mijo también se observan en el siglo XIX, intercalando períodos como 180509 y 1830-34 en los que aportaría en torno al $20 \%$ de las entradas, con otros como $1810-19$ y $1825-29$ en los que superó ligeramente el 9\%. En definitiva, en el priorato de 0 Rosal, los cereales de invierno obtuvieron porcentajes muy bajos, sobre todo en el caso del centeno, que suponía el $40,2 \%$ de las entradas en la granja portuguesa y el $31,2 \%$ en Panxón; las entradas trigueras tuvieron un mayor peso porcentual que el obtenido en la granja de Silva, que era de tan solo el 7,2\%, muy por debajo del de Panxón con el $20,4 \%$. Sin embargo, lo novedoso de la situación de este cereal, en el priorato de O Rosal, fue que ocupó el segundo lugar, detrás del maíz, cuando lo normal era que dicho puesto fuera para el centeno como ocurría tanto en la casa central como en los otros dos prioratos analizados. De lo que no hay duda es de que el maíz, que logró colarse en la renta foral en el siglo XVII, supuso una revolución en el campo, posibilitando el crecimiento de la población, mientras que la demanda de esta, recíprocamente, fue la causante del rápido desarrollo de dicho cereal. ${ }^{23}$ Su importancia ya ha quedado de

22 La inexistencia de la renta de mijo en el siglo XVIII en el priorato de Panxón es confirmada también por Pegerto Saavedra y en la granja de Silva señala que en la década de 1620 la renta sabida "estaba formada en un 49,25 por cien por mijo, y en 43,5 por cien de centeno y en 7,2 por trigo", cfr. en Saavedra, P. 2009. "Composición y trayectoria de las rentas de algunos monasterios cistercienses a lo largo de la Época Moderna", en R. Casal, J. M. Andrade y R. López (eds.): 282.

23 Sobre la importancia de la penetración del maíz en España véase el artículo de Pérez García, J. M. 2007. “La España Agraria septentrional durante el Antiguo Régimen (1500-1850)". Studia Histórica. Historia Moderna, Universidad de Salamanca, 29: pp. 83-129. manifiesto en los prioratos de Silva y Panxón, donde rondaban el $50 \%$ de los ingresos cerealeros, por cuanto en 0 Rosal el peso porcentual superó el $60 \%$, lo que parece evidenciar que las rentas forales estipuladas en cantidades fijas por la comunidad de Oia mostraron una gran sensibilidad a los tipos de cultivo, y, por lo tanto, a la coyuntura agraria de la zona, aunque su influencia no fuese igual en sus diferentes unidades administrativas. ${ }^{24}$ Así, mientras que en Silva y Panxón el cereal americano desplazó por completo al mijo, en O Rosal resistió mejor la competencia no lograron desaparecer en ningún momento.

Los ingresos de vino también eran recaudados por los monjes de Oia en los tres centros geográficos. Su evolución presenta fases bien diferenciadas.

TABLA 4

Evolución de los ingresos anuales de vino en
los prioratos de Oia (1720-1834)

\begin{tabular}{|c|c|c|c|c|c|c|}
\hline & \multicolumn{2}{|c|}{ Panxón } & \multicolumn{2}{c|}{ Silva } & \multicolumn{2}{c|}{ O Rosal } \\
\hline Años & Litros & Índice & Litros & Índice & Litros & Índice \\
\hline $1720-24$ & 2.304 & 180 & 1.824 & 156 & - & - \\
\hline $1725-29$ & 1.516 & 118 & 1.364 & 117 & - & - \\
\hline $1730-34$ & 1.281 & 100 & 1.169 & 100 & - & - \\
\hline $1735-39$ & 1.416 & 111 & 1.032 & 88 & - & - \\
\hline $1740-44$ & 3.893 & 304 & 2.138 & 183 & - & - \\
\hline $1745-49$ & 2.006 & 157 & 1.901 & 163 & - & - \\
\hline $1750-54$ & 2.442 & 191 & 2.634 & 225 & - & - \\
\hline $1755-59$ & 1.552 & 121 & 1.702 & 146 & - & - \\
\hline $1760-64$ & 2.234 & 174 & 2.053 & 176 & - & - \\
\hline $1765-69$ & 1.764 & 138 & 1.899 & 162 & 2.224 & 100 \\
\hline $1770-74$ & 1.845 & 144 & 2.432 & 208 & 2.259 & 102 \\
\hline $1775-79$ & 2.043 & 160 & 1.896 & 162 & 3.203 & 144 \\
\hline $1780-84$ & 1.240 & 97 & 1.672 & 143 & 2.703 & 122 \\
\hline $1785-89$ & - & - & 1.925 & 165 & 5.092 & 229 \\
\hline $1790-94$ & - & - & 1.885 & 161 & 4.781 & 215 \\
\hline $1795-99$ & - & - & 1.115 & 95 & 3.200 & 144 \\
\hline $1803-04$ & - & - & 2.033 & 174 & 3.324 & 149 \\
\hline $1805-09$ & - & - & 1.538 & 132 & 3.027 & 136 \\
\hline $1810-14$ & - & - & 1.562 & 134 & 2.259 & 102 \\
\hline $1815-19$ & - & - & 1.729 & 148 & 2.983 & 134 \\
\hline $1820-24$ & - & - & 3.333 & 285 & 3.441 & 155 \\
\hline $1825-29$ & - & - & 3.070 & 263 & 2.865 & 129 \\
\hline $1830-34$ & - & - & 2.542 & 218 & 2.400 & 108 \\
\hline
\end{tabular}

Fuente: Clero, L: $10.147,10.226$ y 10.228 , AHN

Lamentablemente, las fuentes no permiten completar la serie en los prioratos de Panxón y O Rosal, pero sirven para demostrar la irregularidad de las entradas de vino en los tres prioratos. Los máximos oscilaron entre los 3.893 litros

24 Pegerto Saavedra señala que las rentas forales de Oia se componían en 1630 "en un 13,4 por cien de trigo, un 54,2 de centeno, un 28,7 de mijo y un 3,7 de cebada, mientras en 1702 los porcentajes eran, por el mismo orden, del 7,5, 37, 2,2 y 3,7 ocupando ahora el maíz la primera posición con el 49,6 , por eso en los ingresos generales de la panera el maíz aparece en todo el siglo XVIII como el cereal mayoritario", Saavedra, P. 2009: 282. 
anuales de Panxón en 1740-44, los 3.333 de Silva en 182024 o los 5.092 de 0 Rosal en 1785-89. Por otro lado, prácticamente, no existieron series de años en los que se pueda observar un aumento o disminución continuada de la renta a excepción de 1820-34 cuando se produjo un descenso de las entradas de vino que rondó el $23 \%$ en el priorato de Silva y el $30 \%$ en $\mathrm{O}$ Rosal. En el resto de los períodos las fluctuaciones, al alza y a la baja, fueron constantes, aunque no esconden la importancia que las entradas vitícolas tuvieron en los tres prioratos. Unas entradas con diferente procedencia como demuestran los datos obtenidos en Panxón (17201729) donde se recibió el $76 \%$ del total de su propia reserva, es decir, dentro de su dominio tenían una zona dedicada al cultivo de la vid, el $15,2 \%$ de las compras, el $6,8 \%$ de la renta y el $1,8 \%$ de quintos.

Para conocer la importancia que las ventas de cereal tuvieron en estos centros administrativos se han analizado los resultados de la granja portuguesa de Silva y del priorato gallego de O Rosal entre 1730 y 1794 poniéndolos en relación con los ingresos totales recibidos.

TABLA 5

Porcentajes anuales de las ventas de cereal sobre el recibo total en Silva y O Rosal (en ferrados)

\begin{tabular}{|c|c|c|c|c|c|c|}
\hline & \multicolumn{3}{|c|}{ Silva } & \multicolumn{3}{c|}{ O Rosal } \\
\hline Años & Recibo & Ventas & $\%$ & Recibo & Ventas & $\%$ \\
\hline $1730-34$ & 841 & 677 & 80,5 & - & - & - \\
\hline $1735-39$ & 857 & 669 & 78,0 & - & - & - \\
\hline $1740-44$ & 899 & 675 & 75,0 & - & - & - \\
\hline $1745-49$ & 831 & 646 & 77,7 & - & - & - \\
\hline $1765-69$ & - & - & - & 5.353 & 4.817 & 90,0 \\
\hline $1770-74$ & - & - & - & 5.336 & 4.867 & 91,2 \\
\hline $1775-79$ & - & - & - & 5.272 & 4.816 & 91,3 \\
\hline $1780-84$ & 778 & 467 & 60,0 & 5.375 & 4.835 & 89,9 \\
\hline $1785-89$ & 771 & 482 & 62,5 & 5.344 & 4.879 & 91,3 \\
\hline $1790-94$ & 795 & 526 & 66,2 & 5.307 & 4.799 & 90,4 \\
\hline
\end{tabular}

Fuente: Clero, L. 10.226 y 10.228 , AHN
Aunque las series no son totalmente homogéneas sirven para demostrar dos cosas: la mayor importancia de las entradas de cereal en el priorato de O Rosal, frente a las del litoral portugués, y que el capítulo de las ventas fue más importante en el citado priorato pues rondaba el $90,5 \%$ entre 1780 y 1794 , frente al $62,9 \%$ de la sede de Silva, que tuvo en los años treinta el momento más álgido con el $80,5 \%$ del total. Individualmente, también existieron diferencias por cuanto en Silva se vendió trigo, centeno y maíz (tabla 6), y en O Rosal habría que añadirle la comercialización del otro cereal de primavera: el mijo (tabla 7). Estos contrates se manifiestan en los porcentajes comercializados durante todo el período en cada una de las especies. Así, las ventas trigueras de Silva representaron el $56,5 \%$ de las entradas de este producto entre 1730 49 y el $48,1 \%$ a partir de 1780 ; en O Rosal los porcentajes fueron del $80,6 \%$ entre $1765-79$ y del $81,7 \%$ entre 1780 94. Los resultados del otro cereal de invierno, el centeno, fueron, por el mismo orden, del $88 \%$ y $71,1 \%$ en Silva, y del $90,6 \%$ y $83,8 \%$ en O Rosal. El maíz $73-58,1 \%$ en la granja portuguesa y $93,7-94,1 \%$ en el priorato gallego. El elevado porcentaje de las ventas de cereal se confirma en el priorato de O Rosal con los porcentajes obtenidos para el mijo: $86,9 \%$ en la primera fecha y $88,2 \%$ en la segunda. Estos resultados demuestran que después de la deducción hecha para los gastos ordinarios, limosnas, salarios, etc., el porcentaje mayor de los productos en especie que entraban en los prioratos se destinaba a la venta.

Por su parte, el vino, que aparece en las cuentas de la sede portuguesa, se utilizaba para el consumo ordinario, mermas y para el envío de algunos litros a la casa central, siendo las cantidades comercializadas más bien escasas, no llegando algunos años al 3\% de media anual, como en 173539 en el que la casa recibió 1.032 litros y tan solo vendió 27 (tabla 6). A partir de 1740 los porcentajes oscilaron entre el 25-39\% según los años.

Antes de analizar las cantidades totales que percibían en dinero los prioratos, se pueden comprobar los ingresos producto de las ventas, para después compararlos con aquellas. Se han utilizado los datos del priorato de O Rosal por ser la serie más completa.

TABLA 8

Ingresos por ventas en el priorato de 0 Rosal (en ferrados y reales)

\begin{tabular}{|c|c|c|c|c|c|c|c|c|c|c|}
\hline Años & Trigo & Rs & Maíz & Rs & Centeno & Rs & Mijo & Rs & Total & Rs \\
\hline $1765-69$ & 516 & 5.956 & 3.114 & 20.860 & 575 & 4.250 & 612 & 2.574 & 4.817 & 33.639 \\
\hline $1770-74$ & 529 & 6.155 & 3.092 & 19.728 & 580 & 3.979 & 666 & 2.600 & 4.867 & 32.462 \\
\hline $1775-79$ & 426 & 5.165 & 3.162 & 19.839 & 590 & 3.806 & 637 & 2.483 & 4.816 & 31.292 \\
\hline $1780-84$ & 481 & 6.481 & 3.127 & 26.302 & 572 & 4.541 & 654 & 3.393 & 4.835 & 40.717 \\
\hline $1785-89$ & 502 & 7.403 & 3.116 & 24.111 & 590 & 4.433 & 671 & 2.792 & 4.879 & 38.739 \\
\hline $1790-94$ & 515 & 8.165 & 3.067 & 28.764 & 592 & 5.191 & 625 & 3.622 & 4.799 & 45.742 \\
\hline $1795-99$ & 509 & 10.088 & 2.957 & 34.614 & 570 & 6.022 & 644 & 4.374 & 4.680 & 55.098 \\
\hline
\end{tabular}

Fuente: Clero, L. 10.228, AHN 
Las diferencias existentes entre 1765-1799 estuvieron relacionadas con el movimiento de los precios de los granos, aunque tampoco se puede olvidar que en algunos años el volumen de renta que se comercializó fue menor. Así, las ventas trigueras en la década de los noventa fueron inferiores a las del decenio $1765-74$, siendo los ingresos monetarios muy superiores ya que el promedio de venta fue de 19,8 reales el ferrado y de 11,5 respectivamente. Las cantidades de centeno comercializado prácticamente se mantuvieron estables, aunque los ingresos variaron de forma considerable como demuestran los 575 ferrados que se vendieron anualmente entre $1765-69$, por los que el priorato recibió 4.250 reales, o los 570 del último quinquenio con 6.022 reales de ingresos. Las fluctuaciones más importantes en los precios correspondieron al maíz cuyo incremento llegó a alcanzar el $65 \%$ entre los años sesenta y el último período de los noventa a pesar de venderse 157 ferrados menos. Situación muy similar se produjo con el otro cereal de primera que casi duplicó los ingresos entre los años sesenta y noventa y cuyo promedio de venta anual fue de 4,2 reales en la primera fecha y de 6,7 reales en la segunda. En consecuencia, las cantidades de cereal que salieron de la panera de $\mathrm{O}$ Rosal fueron prácticamente estables a lo largo del período. Todo parece indicar que el prior no reservaba los granos a la espera de años con precios más altos a pesar de que la variable de la curva de los ingresos monetarios condicionaba el útil enviado a la casa central. ${ }^{25}$

El análisis de los ingresos totales en metálico, para las mismas fechas en las que existen datos de las ventas del priorato de O Rosal (1765-1799), permiten comprobar que el porcentaje de las ventas sobre los ingresos rondó el $85 \%$ como media en todo el período; claro indicador, por lo tanto, de la importancia que para este priorato tenían los ingresos en metálico producto de las ventas y de la escasa participación de los ingresos no procedentes de la comercialización.

TABLA 9

Medias anuales de las ventas y porcentajes sobre los ingresos totales en el priorato de 0 Rosal (reales y porcentajes)

\begin{tabular}{|c|c|c|c|}
\hline Años & Ingresos & Ventas & $\%$ \\
\hline $1765-69$ & 41.484 & 33.639 & 81,1 \\
\hline $1770-74$ & 42.966 & 32.462 & 75,6 \\
\hline $1775-79$ & 38.074 & 31.292 & 82,2 \\
\hline $1780-84$ & 46.143 & 40.717 & 88,2 \\
\hline $1785-89$ & 45.124 & 38.739 & 85,9 \\
\hline $1790-94$ & 50.960 & 45.742 & 89,8 \\
\hline $1795-99$ & 60.502 & 55.098 & 91,1 \\
\hline
\end{tabular}

Fuente: Clero, L. 10.228, AHN

Por su parte, las entradas en dinero de los tres prioratos ponen de manifiesto las diferencias existentes entre ellos así como la evolución de los índices. El priorato de Panxón

25 Sobre las prácticas especulativas en otros cenobios castellanos véase a García Martín, P. 1983. “El arca de reserva del monasterio de San Benito el Real de Sahagún. Un mecanismo de acaparamiento de granos en el mercado leonés del siglo XVIII". Tierras de León 53: 71-80; López García, J. M.1990: 324. ofrece unos resultados con continuas fluctuaciones tanto en el apartado de ingresos nominales como en el de sus correspondientes índices con máximos que se alcanzaron en 1750-1754, cuando recibe 10.929 reales de media y el índice fue de 128 (tabla 10). Las diferencias son también muy marcadas al fijarse en los índices del útil que estuvieron siempre muy por encima de los ingresos brutos, presentando además oscilaciones menos acusadas y con períodos como $1730-1754$ en los que hubo un ascenso continuado de los índices, para descender nuevamente en la década siguiente y volver a recuperarse en 1765-1769, momento en el que se alcanzó el valor más alto con un índice de 231 y un útil de 7.088 reales que fue lo que finalmente se envió a la casa central. En su momento, se analizará la evolución del gasto y su influencia sobre el útil, pero se puede adelantar que la escasa importancia de los gastos frente a los ingresos, que no presentan además variaciones muy acentuadas, permitió a este priorato ofrecer un útil elevado a la casa central en relación con sus entradas en dinero (gráfico 1).

En la granja de Silva (tabla 11) se refleja una situación similar a la de Panxón en el capítulo de ingresos nominales, con constantes variaciones al alza y a la baja, aunque con períodos como 1740-54 que tuvieron un crecimiento continuo. A partir de esta fecha la estabilidad fue la norma hasta los años diez del XIX, cuando el índice se elevó a 150 como consecuencia del ascenso de las entradas en dinero con respecto al quinquenio anterior; desde este momento hubo un descenso continuado hasta el final del período. Por su parte, los índices del útil fueron más parejos a los de los ingresos (gráfico 2), alcanzándose los valores más altos cuando los ingresos fueron superiores -1740-54 y 1810-14-y en correlación con las caídas en las partidas de gastos.

La situación del priorato de O Rosal sería distinta tanto por las diferencias que ofrecen los resultados de los índices como por la importancia de los ingresos y, por tanto, del útil enviado a la casa central, ocupando un destacado primer puesto. La tabla 12 refleja un recibo que creció prácticamente sin interrupciones hasta 1814 y sufrió una caída importante a partir de ese momento, llegando a alcanzar los valores más bajos con unos ingresos anuales de 33.258 reales en el quinquenio 1830-34. El movimiento de los índices de los ingresos y del útil (gráfico 3) tuvo unos valores parecidos, con períodos como el de 1780-84 en el que llegaron a coincidir y con unos índices al alza, en ambos casos, hasta 1814, iniciándose desde ahí un descenso coincidente con el gran tirón de los índices de gastos. En los tres últimos quinquenios el recibo total siguió descendiendo, de la misma forma que los gastos, aunque los índices de estos quedaron muy por encima de los ingresos. Así, el útil refleja que en sus momentos finales el priorato de O Rosal presentó un descenso considerable de sus beneficios. ${ }^{26}$

La estructura de los ingresos se ha analizado a través de las catas realizadas en el priorato gallego de Panxón y en la granja portuguesa de Silva. Los resultados de los gráficos 4 y 5 demuestran, en primer lugar, la variedad de partidas por las que recibió ingresos el priorato de Panxón frente al de Silva en el que solo se registraron cinco conceptos. La mayor

26 Se remite la comparación de estos datos a los de los prioratos cistercienses orensanos analizados por Rionegro Fariña, I. 1998. La estructura económica del císter orensano en la fase final del Antiguo Régimen: 37. Ourense: Caixa Ourense. 
diferencia se produjo por la comercialización del cereal y vino pues si en el priorato gallego representaba el 61,6\% del total, en la granja portuguesa las entradas procedentes de las ventas alcanzaron el $92,2 \%$ de los ingresos. De las otras partidas cabe destacar el $27,6 \%$ de la renta cobrada en dinero en Panxón y el 5,2\% en Silva. El padre administrador de Panxón percibía además con regularidad diversos censos en metálico que producían el $4 \%$ de las entradas anuales. El resto de los ingresos se completaban con partidas diversas, como la cera, vasallaje, verbos, décimas y luctuosas e incluso algunas ventas como la realizada en 1761 por la granja de Silva de "una caldera en 16 rs, un gergón viejo en $6 \mathrm{rs}$, una manta vieja en $10 \mathrm{rs}, 2$ azadones y una machada en $14 \mathrm{rs}$, una docena de platos, 2 medias fuentes y dos almofías de peltre en $32 \mathrm{rs}^{\prime \prime} ;{ }^{27}$ partidas que no tuvieron relevancia pues rondaron el $1 \%$ o no llegaron a alcanzarlo.

Resumiendo. Se han analizado hasta aquí los ingresos de los prioratos con el objetivo de medir la importancia que para la casa central tenían unas unidades administrativas encargadas de comercializar sus respectivos productos, además de cubrir sus gastos monetarios, remitiendo al finalizar el año contable las rentas líquidas a la abadía matriz. Precisamente, es el capítulo de gastos el que corresponde estudiar ahora para conocer cómo y de qué manera los prioratos oienses empleaban los ingresos monásticos.

\section{LOS GASTOS DE LOS PRIORATOS}

Evidentemente, y a diferencia de lo que ocurría con las casas centrales, los prioratos se encargaban sobre todo de absorber numerario, debido a su especialización en la comercialización de los granos que recibían y del reducido capítulo de gastos centrado en el sostenimiento del prior, el alimento del ganado, las limosnas o la remuneración de la mano de obra asalariada; lo restante, como queda dicho, se destinaba a la venta. Este modelo, al igual que sucedía en otras granjas cistercienses, es aplicable a los prioratos del sudoeste gallego. ${ }^{28}$

Por lo que se refiere a las salidas anuales en especie de los prioratos se puede confirmar que concuerdan con la composición de los ingresos. Así, en el priorato de Panxón las salidas del maíz representaron el $48,5 \%$, las de centeno el $31,1 \%$ y las de trigo el $20,3 \%$; en O Rosal los resultados fueron del $63,1 \%$ para el maíz, el mijo $13,9 \%$, y el centeno y el trigo en torno al 11\%; en la granja portuguesa de Silva el maíz 52,3\%, el centeno $40,4 \%$ y el trigo 7,3\%. Se advierte además que sus administradores empleaban las cantidades más voluminosas en las ventas del propio cereal y del vino, lo que se confirma al observar los porcentajes de los otros gastos en dos de los prioratos del monasterio del litoral marítimo: Silva y O Rosal.

\footnotetext{
27 Clero, L: 10.226, AHN.

28 Sobre las salidas de otras granjas cistercienses véase a Brumont F. 1979. "Comptes d'exploitations et historie économique: l'exemple de la "granja" de Quintanajuar". Melanges de la Casa de Velázquez XV: 385-414; Charles, J. 1984. "Production céréalière, autoconsommation et marché: la grange cistercinne de Cendrera (1630-1711). Congreso de Historia Rural. Siglos XVI-XIX: 809-826. Madrid: Casa de Velásquez: Universidad Complutense; López García, J. M. 1990: 365.
}

TABLA 13

Porcentajes de los gastos de cereal y vino en el priorato de Silva (1730-1794)

\begin{tabular}{|c|c|c|c|c|}
\hline Años & Trigo & Centeno & Maíz & Vino \\
\hline $1730-34$ & 38,9 & 5,6 & 27,3 & 88,9 \\
\hline $1735-39$ & 42,6 & 9,5 & 28,4 & 97,4 \\
\hline $1740-44$ & 46,1 & 20,0 & 25,7 & 61,0 \\
\hline $1745-49$ & 46,1 & 12,6 & 26,5 & 63,9 \\
\hline $1780-84$ & 52,2 & 32,6 & 44,5 & 69,4 \\
\hline $1785-89$ & 54,3 & 31,1 & 40,7 & 75,0 \\
\hline $1790-94$ & 49,2 & 23,0 & 40,3 & 65,3 \\
\hline
\end{tabular}

Fuente: Clero, L. 10.226, AHN

En el priorato de Silva hay que destacar la importancia que las ventas de centeno y maíz tuvieron entre 1730 y 1794 al comprobar los porcentajes obtenidos por las salidas que tenían como destino prioritario el consumo ordinario, es decir, el mantenimiento del prior y sus criados, las partidas destinadas a los huéspedes y limosnas, los salarios o el consumo animal. Los porcentajes del trigo presentan unos valores más altos y prácticamente estáticos en todo el período. Lógico si se tiene en cuenta que este cereal era el más apreciado como alimento lo que llevaba a los monjes granjeros a destinar aproximadamente el $47 \%$ de lo recibido para su propio consumo, utilizando el $53 \%$ restante para las ventas. A diferencia de lo que ocurría con los cereales, la mayor parte de los ingresos de vino estaban supeditados al consumo de la familia monástica y a los envíos a la casa central, con porcentajes que descendieron de forma considerable desde los años cuarenta, pero que siempre represenron más del $60 \%$ de los ingresos totales. ${ }^{29}$

TABLA 14

Porcentajes de los gastos de cereal en el priorato O Rosal (1765-1794)

\begin{tabular}{|c|c|c|c|c|}
\hline Años & Trigo & Centeno & Maíz & Mijo \\
\hline $1765-69$ & 15,9 & 16,2 & 6,2 & 16,7 \\
\hline $1770-74$ & 12,6 & 15,3 & 6,6 & 9,3 \\
\hline $1775-79$ & 29,6 & - & 5,9 & 13,2 \\
\hline $1780-84$ & 21,2 & 20,3 & 5,4 & 11,6 \\
\hline $1785-89$ & 19,0 & 14,0 & 5,6 & 8,8 \\
\hline $1790-94$ & 14,5 & 14,1 & 6,5 & 15,0 \\
\hline
\end{tabular}

Fuente: Clero, L. 10.228, AHN

Los resultados de O Rosal entre 1765 y 1794 confirman, una vez más, que la mayor porción de los ingresos cerealeros se comercializaba después de satisfacer el consumo interno. A este se destinaba el $18,8 \%$ de las entradas de trigo, $12,8 \%$ de las de centeno, $6 \%$ de las de maíz y $12,4 \%$ de las de mijo. De todas formas en algunos períodos -1775-79- las ventas de centeno superaron a las cantidades recibidas; probablemente, cuando esto ocurría los monjes granjeros recurrieron a las escasas cantidades que debían tener en depósito, dado el

29 Pueden establecerse comparaciones con el priorato de San Bartolomé, dependiente de Montederramo, estudiado por Rionegro Fariña, I. 1998: 44. 
bajo consumo de estas administraciones periféricas. ${ }^{30}$ Los dos cereales de invierno, trigo y centeno, presentan unos porcentajes muy similares en toda la serie, excepción hecha del quinquenio $1775-79$, y su consumo se destinaba al gasto ordinario además de otras partidas como las sembraduras, las limosnas o los salarios; el mismo destino, aunque en proporciones más pequeñas, tenían el maíz y el mijo.

El gasto en dinero de los prioratos vuelve a poner de manifiesto las diferencias existentes entre ellos. Los resultados que ofrece Panxón (tabla 15) son prácticamente estables entre 1720-83, con la salvedad de algunos años -1735-39en los que se empleaban anualmente 6.950 reales, obteniéndose el índice más elevado -127- y produciéndose además un aumento de los ingresos, aunque de menor cuantía. A partir de aquí las oscilaciones fueron pequeñas, tanto en su evolución como en las cantidades que desembolsaba el monje granjero para los gastos ordinarios y extraordinarios. De hecho, en todo el período las salidas anuales se situaron en una media de 3.478 reales lo que pone de manifiesto que la sede prioral no pasó por grandes apuros económicos y siguió a rajatabla la lógica de funcionamiento de estas unidades, encargadas de generar ingresos a través de la comercialización de los cereales en las localidades de cobranza y con unos gastos que, a pesar de superar los 3.000 reales anuales, no alcanzaron el $40 \%$ de los ingresos.

En la granja portuguesa de Silva la trayectoria del gasto (tabla 16), entre los años veinte y ochenta del XVIII, fue similar a la de Panxón, índices prácticamente estables, exceptuando pequeñas oscilaciones y alcanzándose los valores más altos en 1735-39 con una media anual de 3.323 reales y un índice de 106. A partir del siglo XIX la situación se agravó pues el aumento del gasto prácticamente se duplicó entre los dos primeros quinquenios llegando a superar en 1805-09 los ingresos recibidos en un $14,7 \%$ y, por consiguiente, presentando un saldo negativo. Entre 1810-14 la curva de gastos presenta una nueva reducción que llegó hasta 1815-19 durante los cuales el crecimiento del gasto, en torno al $13 \%$, fue parejo al descenso de los ingresos. Desde el Trienio Liberal el gasto se redujo, sobre todo, por la menor incidencia de las contribuciones, aunque no lo hizo en la misma medida que los ingresos pues hay que tener en cuenta que el gasto ordinario siempre cuenta con unas partidas fijas que no se pueden eludir. ${ }^{31}$

El priorato de O Rosal (tabla 17) presenta unas circunstancias que se pueden considerar excepcionales como consecuencia de la escasa relevancia que tiene el gasto sobre los ingresos, a pesar de que su curva presenta una elevación

30 P. Saavedra al analizar la evolución de los alcances de los prioratos de Castro de Rei y Solme, dependientes el primero del monasterio de Montederramo y el segundo de Sobrado, señala que "los voluminosos alcances nada tenían que ver con el consumo, muy reducido en los prioratos y granjas, su descenso parece apuntar a la aparición de mecanismos de comercialización del cereal caracterizados por una mayor agilidad, pues las ventas tienen lugar año a año, sin almacenamientos voluntarios o forzosos." Saavedra, P. 2008. "La comercialización de las rentas agrarias en la Galicia del Antiguo Régimen”. Obradoiro de Historia Moderna 17: 257-258.

31 Así, por ejemplo, en 1830-1831 los gastos en alimentación representan el 35\% del gasto total, empleándose 132 reales en la adquisición de aceite, 26 en arroz, 20 en azafrán, 22 en azúcar, 300 en carne, 322 en pescado, 23 en garbanzos, 12 en huevos y 34 en sal, además de otras partidas fijas como los 500 reales que desembolsaban en salarios. Clero, L: 10.226, AHN. casi constante hasta los años veinte del XIX, exceptuando los ochenta, en los que se produce un pequeño descenso de los índices con respecto a los años setenta, consecuencia de los 4.837 reales que se gastaron frente a los 5.422 del quinquenio 1775-79. En los períodos inmediatamente posteriores al Trienio se produjo un descenso del gasto, pero al igual que ocurría en la granja portuguesa, sus índices superaron a los de los ingresos, evidentemente, había que seguir manteniendo la compra de determinados alimentos - pescado, carne, legumbres, aceite, especies, aceitunas, dulces- de los vestidos o hacer frente a los salarios.

GráfICO 6

\section{Porcentaje de gasto sobre recibo en Silva, O Rosal y Panxón (1720-1834)}

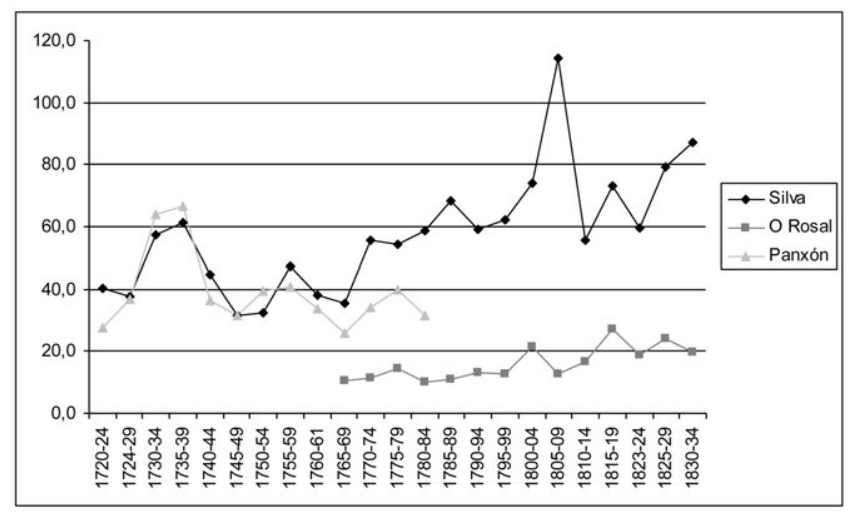

Fuente: Clero, L. 10.147 , L. 10.226 y 10.228 , AHN

En cuanto a la incidencia de los gastos sobre el recibo en dinero de los tres prioratos (1720-1834) se confirma como en Panxón y la granja de Silva fue elevado, con máximos del $66,4 \%$ en la sede gallega en $1735-39$ y superando el $100 \%$ en Silva en 1805-09, cuando se obtiene un saldo negativo por superar los gastos a los ingresos. En O Rosal solo se conocen los datos posteriores a 1765 , sin embargo, no deja de sorprender que este solo constituye el $15 \%$ del total en todo el período, a pesar de que existieron años -1815-19- en los que tal porcentaje alcanzó el 27,3\%. Precisamente, como consecuencia de la evolución de ingresos y gastos de cada priorato se puede conocer el útil que finalmente era enviado a la casa central. Los valores absolutos marcan importantes diferencias. Así, el priorato de Panxón envía anualmente a Oia 5.301 reales, Silva 2.213 y O Rosal 39.843. Es evidente, por lo tanto, que O Rosal fue el mayor portador de útil a la casa central que además presentó una evolución favorable hasta 1815. Desde este momento descendió de forma brusca hasta el final del período como consecuencia, no tanto de la reducción del gasto, sino del importante descenso del ingreso provocado por la frecuencia de los impagos y la caída de los precios, lo que, indudablemente, tendría resultados negativos para la economía de la casa central. ${ }^{32}$

32 La situación de endeudamiento de las casas cistercienses, con diferencias entre unas y otras, ya ha sido analizada, entre otros, por Burgo López, Mạ C. 1988. "La conflictividad en torno al pago de la renta foral en Galicia a fines del antiguo régimen". Espacio, tiempo y forma, 4: 135-150; Rey Castelao, O. 1991. "La crisis de la economía de las instituciones eclesiásticas de Galicia”, en P. Saavedra y R. Villares (coord.), Señores y campesinos en la Península Ibérica, siglos XVIII- XX: 261-303. Santiago; P. Saavedra. 2008: 261-303. 


\section{CONCLUSIONES}

Las instituciones monásticas como Santa María de Oia, del mismo modo que otros cenobios gallegos, obtenían la mayor parte de sus ingresos de su condición de rentistas agrarios, explotando importantes dominios a través de los contratos forales. En este sentido, hay que hablar de un modelo propio en Galicia frente a la importancia que para las economías monásticas castellanas tenía la explotación directa de su dominio. En cuanto a los gastos se derivaban, principalmente, de la manutención de los monjes y del personal a su servicio, además de la conservación de su patrimonio. Un patrimonio compuesto por un conjunto de bienes cercanos a la casa central y otros más alejados gestionados por administraciones autónomas que actuaban como enclaves fundamentales para la percepción de las rentas y la vigilancia del patrimonio monástico. Pero también como centros de comercialización en los que vendían cereal, vino y otros productos que no se enviaban a la casa central. Partiendo de esta premisa, en este artículo se ha analizado la situación económica de tres prioratos dependientes del monasterio situado en el litoral gallego. Se han cuantificado los ingresos en especie comprobando que el maíz era el cereal más abundante en los dos prioratos gallegos de Panxón y $\mathrm{O}$ Rosal y en el portugués de Silva. Distinto comportamiento tuvieron otros cereales como el centeno y el trigo que ocupaban la segunda y tercera posición en Panxón y Silva, pero que se vieron superados por el mijo en la sede de O Rosal. Es evidente, por lo tanto, que en los dos primeros el maíz, que logró colarse en la renta foral en el XVII, desplazó por completo al mijo, mientras que en O Rosal resistió mejor la competencia no logrando desaparecer en ningún momento. La mayor parte del cereal que llegaba a las sedes priorales, después de satisfacer el consumo interno, se destinaba a la venta lo que generaba importantes ingresos en numerario que les permitía cubrir los gastos en dinero y remitir el útil obtenido al final de cada ejercicio a la casa central.

En síntesis, la acertada gestión del monasterio de Oia, en la que unas cuantas filiales supervisaban la explotación de las propiedades, le permitió disfrutar de una favorable situación económica hasta que se inició la crisis de fines del Antiguo Régimen en el último tercio del siglo XVIII.

\section{BiBLIOgRAFÍA}

Brumont, F. 1979. "Comptes d'exploitations et historie économique: l'exemple de la "granja" de Quintanajuar". Melanges de la Casa de Velázquez XV: 385-414.

Burgo López, Ma C. 1988. "La conflictividad en torno al pago de la renta foral en Galicia a fines del antiguo régimen". Espacio, tiempo y forma, 4: 135-150.

Cendón Fernández, M. 2000. "Santa María de Oia”, en D. Yánez Neira (coord.), Monasticón Cisterciense Gallego V. 1: 203. León: Caixa Vigo e Ourense.

Charles, J. 1984. "Production céréalière, autoconsommation et marché: la grange cistercinne de Cendrera (1630-1711). Congreso de Historia Rural. Siglos XVI-XIX: 809-826. Madrid: Casa de Velázquez: Universidad Complutense.

Fernández Cortizo, C. J. 2000. "Las reformas de las Órdenes de San Benito y del Cister en Galicia en tiempos de Carlos V", en A. Eiras Roel (coord.), El reino de Galicia en la época del emperador Carlos V: 847-877. Santiago de Compostela: Xunta de Galicia.

García Martín, P. 1983. “El arca de reserva del monasterio de San Benito el Real de Sahagún. Un mecanismo de acaparamiento de granos en el mercado leonés del siglo XVIII". Tierras de León 53: 71-80.
García Martín, P. 1985. El Monasterio de San Benito el Real de Sahagún en la época moderna Valladolid: Junta de Castilla y León.

García Oro, J. y Portela Silva, Ma J. 2002. “El císter gallego en el reinado de Carlos V", en Aproximaciones al reinado de Carlos V: 9-43. A Coruña: Fundación Caixa Galicia.

Llopis Agelán, E. 1980. Las economías monásticas al final del Antiguo Régimen en Extremadura Madrid: Universidad Complutense.

López García, J. M. 1982. “Economía monástica y sociedad rural en Valladolid durante el Antiguo Régimen La Real Cartuja de Nuestra Señora de Aniago", Annales de la Universidad de Alicante 2: 83-134.

López García, J. M. 1990. La transición del feudalismo al capitalismo en un señorío monástico castellano: el Abadengo de la Santa Espina (1147-1835) Valladolid: Junta de Castilla y León.

Meijide Pardo, A. 1980. El comercio del bacalao en la Galicia del siglo XVIII. La Coruña: Diputación Provincial.

Pallares Méndez, Ma del C. y Portela Silva, E. 1971. El bajo Valle del Miño en los siglos XII y XIII. Economía agraria y estructura social. Santiago de Compostela: Universidade de Santiago.

Pérez García, J. M. 2007. "La España Agraria septentrional durante el Antiguo Régimen (1500-1850)". Studia Histórica. Historia Moderna, Universidad de Salamanca, 29: pp. 83-129.

Portela Silva, E. 1976. La región del obispado de Tuy en los siglos XII a XV: una sociedad en la expansión y en la crisis. Santiago de Compostela: El Eco Franciscano.

Rey Castelao, O. 1991. "La crisis de la economía de las instituciones eclesiásticas de Galicia", en P. Saavedra y R. Villares (coord.), Señores y campesinos en la Península Ibérica, siglos XVIII- XX: 261303. Santiago; P. Saavedra. 2008: 261-303.

Rey Castelao, O. 2002. "El clero regular de la diócesis compostelana en la Época Moderna”, en J. García Oro (coord.), Historia de las diócesis españolas: Santiago, Tuy-Vigo: 383-384. Madrid: Biblioteca de Autores Cristianos.

Rionegro Fariña, I. 1998. La estructura económica del císter orensano en la fase final del Antiguo Régimen: 37 . Ourense: Caixa Ourense.

Rodrigues, A. P. 2012. "O tombo de 1560/1565 da granja da Silva do mosteiro de Santa María de Oia. Aspectos da evoluçâo e consolidaçâo do património medieval do mosteiro de Oia no Entre -Limae-Minho português através da análise de um documento de época moderna". Cuadernos de estudios gallegos 125: 115-142.

Rodrigues, A. P. 2012. "Consideraciones sobre la percepción de frontera. En torno al patrimonio del monasterio de Santa María de Oia en Portugal durante la Edad Media". Historia I+D. Revista de estudios históricos: 9-31.

Saavedra, P. 2008. "La comercialización de las rentas agrarias en la Galicia del Antiguo Régimen". Obradoiro de Historia Moderna 17: 257-258.

Saavedra, P. 2009. “Composición y trayectoria de las rentas de algunos monasterios cistercienses a lo largo de la Época Moderna", en R. Casal, J. M. Andrade y R. López (eds.): 282.

Sánchez Carrera, Ma del C. 1997. El Bajo Miño en el siglo XV. El espacio y los hombres. A Coruña: Fundación Pedro Barrié de la Maza.

Sebastián Amarilla, J. A. 1992. Agricultura y rentas monásticas en tierras de León. Santa María de Sandoval (1167-1835) Madrid: Universidad Complutense.

Seijas Montero, M. 2010. Los monasterios cistercienses en el sudoeste gallego a fines del Antiguo Régimen. Santiago de Compostela: Universidade de Santiago.

Seijas Montero, M. 2012. "El patrimonio de los monasterios cistercienses del sudoeste gallego en la Edad Moderna". Hispania 241: 423-452.

Vázquez Lijó, J. M. 2009. "Sabrosa abstinencia: abasto y consumo de pescado en el monasterio de Sobrado (ss. XVII-XVIII)". Obradoiro de Historia Moderna 18: 151-179.

Vázquez Lijó, J. M., y Sandoval Verea, F. M. 2009. “Alimento de vigilias: el pescado en la dieta de los cistercienses gallegos a finales del Antiguo Régimen", en R. Casal, J. M. Andrade y R. López (eds.), Galicia monástica: estudos en lembranza da profesora María José Portela Silva: 333-359. Santiago de Compostela: Universidad de Santiago.

Yáñez Neira, D. 1991. "Los monasterios cistercienses gallegos en la reforma de fray Martín de Vargas", en J. C. Valle Pérez (ed.), El monacato en Galicia durante la Edad Media: la orden del císter: 71-106. Santiago de Compostela: Fundación Alfredo Brañas. 
MAPA 1

Localización de los monasterios cistercienses masculinos en la provincia de Pontevedra.

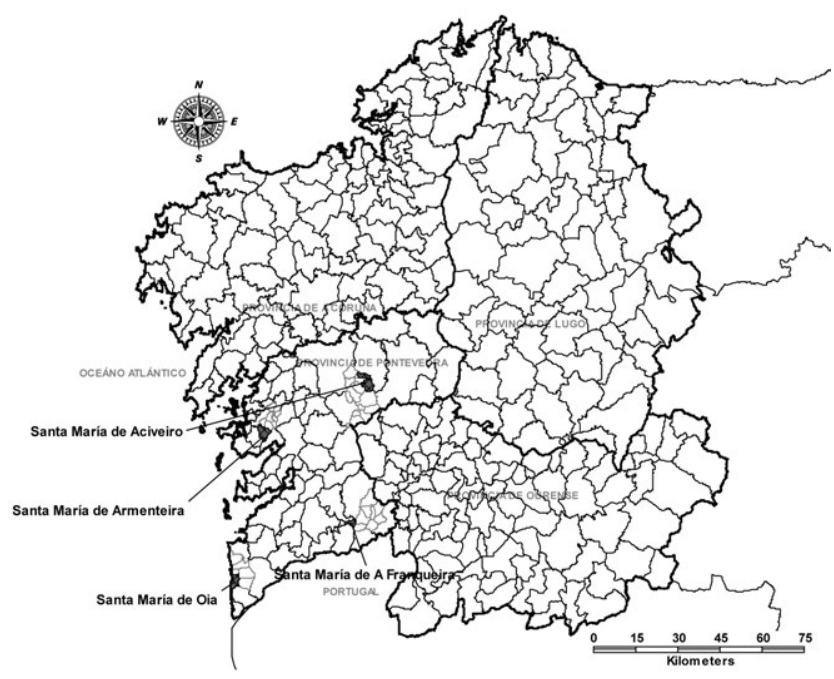

Fuente: Río Barja, Francisco X., Cartografía xurisdicional de Galicia no século XVIII, Santiago, Consello da Cultura Galega, 1990

MAPA 2

Localización de los prioratos de los monasterios cistercienses del sudoeste gallego

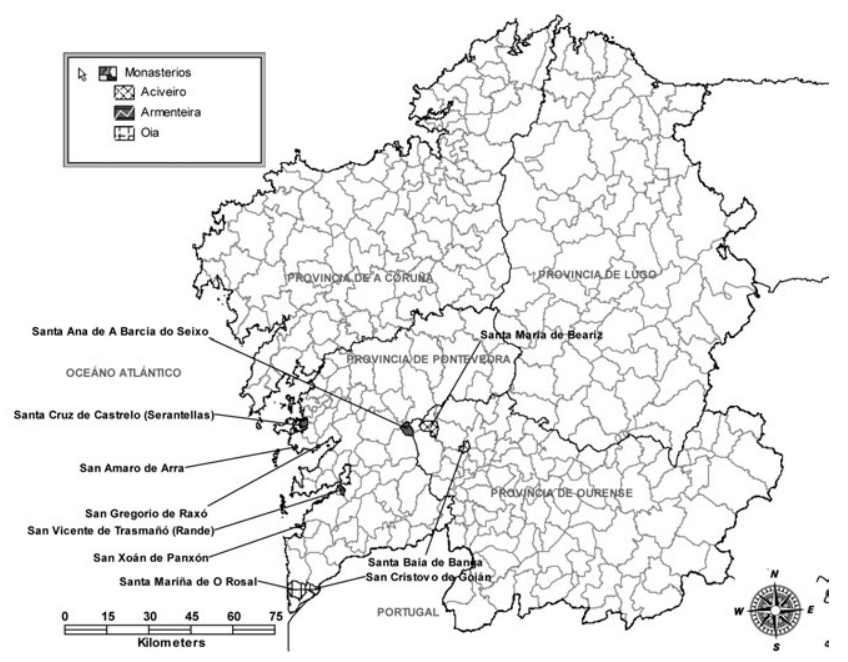

Fuentes: ARG, Fondo Eclesiástico: Inventario General del Monasterio de Acibeiro, 1835, leg. 895-8; ARG, Fondo Eclesiástico: Inventario 3응 del Monasterio de Armentera y sus 5 prioratos. 1821, leg. 454-8; AHPP, Invetarios de bienes monásticos: Inventario del Monasterio de Oya, 1835, G-8366 (Carp. 10-2); AHN, Clero, Li. 10.037 , fols. 214 r y ss.
MAPA 3

Localización de las posesiones de Santa María de Oia en la Granja de Silva (Portugal)

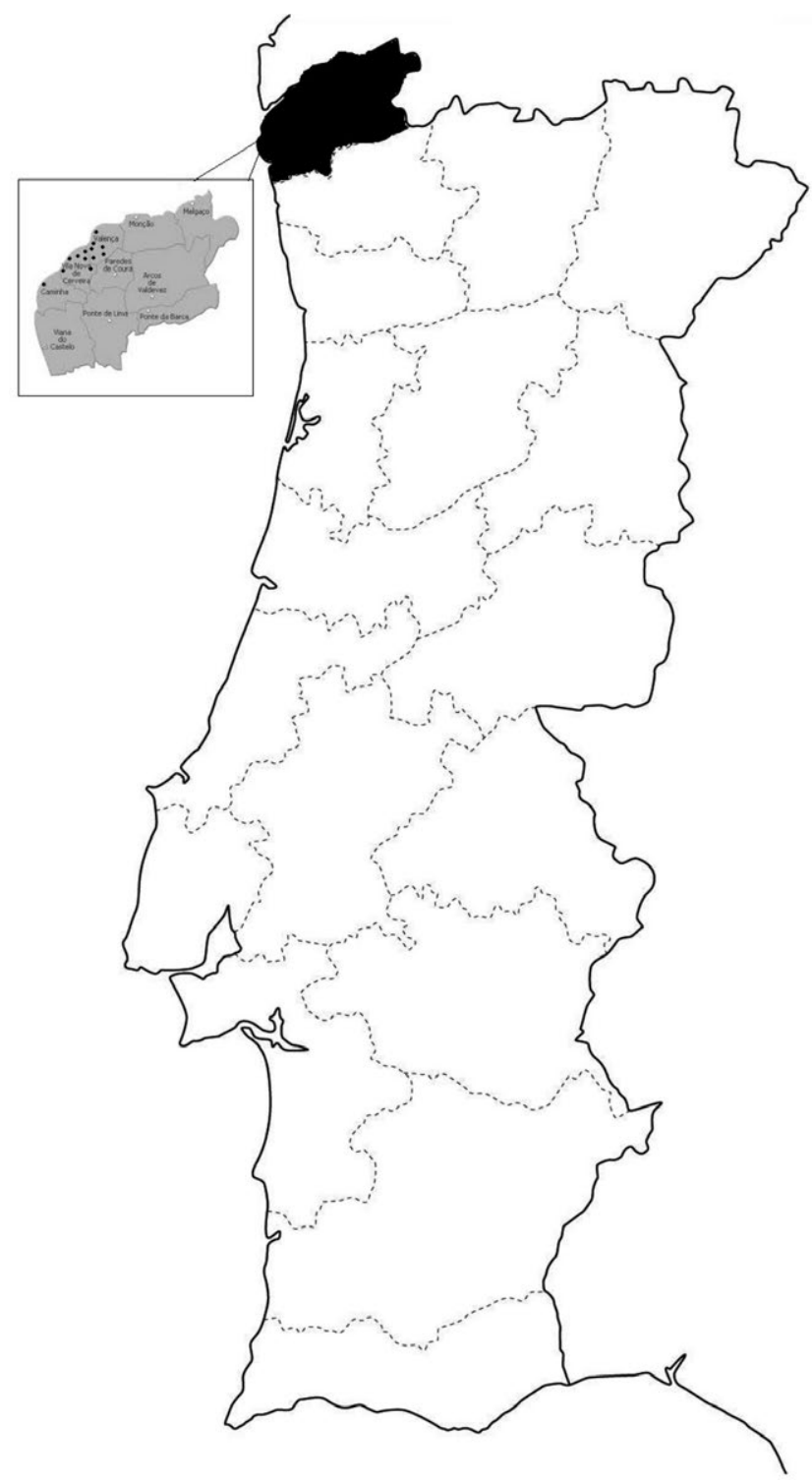

Fuente: AHN, Tumbo de los bienes y propiedades que tenía el monasterio cisterciense de Santa María de Oya en la Granja de Silva y de los bienes a ella anejos en el reino de Portugal, 1560. Códices, L. 1.037. 
TABLA 1

Composición de los ingresos en especie recibidos por el priorato de San Xoán de Panxón (ferrados)

\begin{tabular}{|c|c|c|c|c|c|c|}
\hline Años & Trigo & $\begin{array}{l}\text { Media } \\
\text { Anual }\end{array}$ & Centeno & $\begin{array}{l}\text { Media } \\
\text { Anual }\end{array}$ & Maíz & $\begin{array}{l}\text { Media } \\
\text { Anual }\end{array}$ \\
\hline $1720-24$ & 1.190 & 238 & 1.861 & 372 & 2.791 & 558 \\
\hline $1725-29$ & 1.189 & 238 & 1.790 & 358 & 2.799 & 560 \\
\hline $1730-34$ & 1.187 & 237 & 1.782 & 356 & 2.798 & 560 \\
\hline $1735-39$ & 1.191 & 238 & 1.783 & 357 & 2.800 & 560 \\
\hline $1740-44$ & 1.186 & 237 & 1.793 & 359 & 2.805 & 561 \\
\hline $1745-49$ & 1.191 & 238 & 1.792 & 358 & 2.792 & 558 \\
\hline $1750-54$ & 1.189 & 238 & 1.810 & 362 & 2.792 & 558 \\
\hline $1755-59$ & 1.188 & 238 & 1.790 & 358 & 2.781 & 556 \\
\hline $1760-64$ & 1.186 & 237 & 1.792 & 358 & 2.767 & 553 \\
\hline $1765-69$ & 1.150 & 230 & 1.792 & 358 & 2.757 & 551 \\
\hline $1770-74$ & 1.144 & 229 & 1.793 & 359 & 2.762 & 552 \\
\hline $1775-79$ & 1.142 & 228 & 1.794 & 359 & 2.759 & 552 \\
\hline $1780-83$ & 917 & 229 & 1.433 & 358 & 2.204 & 551 \\
\hline
\end{tabular}

Fuente: Clero, L. 10.147, AHN

TABLA 2

Composición anual de los ingresos en especie recibidos por la granja de Santa María da Silva (ferrados, porcentajes e índice) 1730-34=100

\begin{tabular}{|c|c|c|c|c|c|c|c|c|}
\hline Años & Trigo & $\%$ & Centeno & $\%$ & Maíz & $\%$ & Total & Índice \\
\hline $1720-24$ & 62 & 7,9 & 331 & 42,5 & 386 & 49,6 & 779 & 93 \\
\hline $1724-29$ & 60 & 7,0 & 343 & 39,7 & 461 & 53,4 & 864 & 103 \\
\hline $1730-34$ & 60 & 7,1 & 336 & 40,0 & 445 & 53,0 & 841 & 100 \\
\hline 1735-39 & 62 & 7,2 & 337 & 39,3 & 458 & 53,4 & 857 & 102 \\
\hline $1740-44$ & 61 & 6,8 & 337 & 37,5 & 501 & 55,7 & 899 & 107 \\
\hline $1745-49$ & 57 & 6,8 & 335 & 40,3 & 439 & 52,9 & 831 & 99 \\
\hline $1750-54$ & 58 & 7,1 & 338 & 41,2 & 425 & 51,7 & 821 & 98 \\
\hline $1755-59$ & 52 & 6,6 & 333 & 42,3 & 402 & 51,1 & 788 & 94 \\
\hline $1760-61$ & 64 & 7,5 & 342 & 39,9 & 451 & 52,6 & 857 & 102 \\
\hline $1765-69$ & 56 & 6,8 & 339 & 41,2 & 427 & 52,0 & 822 & 98 \\
\hline $1770-74$ & 53 & 6,5 & 332 & 41,0 & 425 & 52,5 & 809 & 96 \\
\hline $1775-79$ & 47 & 6,1 & 326 & 41,9 & 404 & 52,0 & 776 & 92 \\
\hline $1780-84$ & 49 & 6,3 & 329 & 42,3 & 400 & 51,4 & 778 & 93 \\
\hline $1785-89$ & 49 & 6,4 & 327 & 42,5 & 395 & 51,2 & 771 & 92 \\
\hline $1790-94$ & 51 & 6,4 & 328 & 41,3 & 415 & 52,3 & 795 & 95 \\
\hline 1795-99 & 40 & 18,1 & 57 & 25,9 & 122 & 55,9 & 218 & 26 \\
\hline $1800-04$ & 47 & 8,4 & 204 & 36,8 & 304 & 54,8 & 555 & 66 \\
\hline 1805-09 & 50 & 8,0 & 249 & 40,1 & 321 & 51,9 & 620 & 74 \\
\hline $1810-14$ & 52 & 7,5 & 276 & 40,0 & 363 & 52,5 & 691 & 82 \\
\hline 1815-19 & 52 & 7,5 & 288 & 41,6 & 352 & 50,9 & 692 & 82 \\
\hline $1823-24$ & 49 & 7,1 & 266 & 38,2 & 380 & 54,7 & 695 & 83 \\
\hline $1825-29$ & 52 & 7,7 & 268 & 39,4 & 360 & 52,9 & 680 & 81 \\
\hline $1830-34$ & 52 & 7,5 & 278 & 39,8 & 368 & 52,7 & 698 & 83 \\
\hline
\end{tabular}

Fuente: Clero, L. 10.226, AHN 
TABLA 3

Composición anual de los ingresos en especie recibidos por el priorato de Santa Mariña de O Rosal (ferrados, porcentajes e índice) 1765-69=100

\begin{tabular}{|c|c|c|c|c|c|c|c|c|c|c|}
\hline Años & Trigo & $\%$ & Centeno & $\%$ & Maíz & $\%$ & Mijo & $\%$ & Total & Índice \\
\hline $1765-69$ & 614 & 11,5 & 686 & 12,8 & 3.319 & 62,0 & 734 & 13,7 & 5.353 & 100 \\
\hline $1770-74$ & 605 & 11,3 & 685 & 12,8 & 3.312 & 62,1 & 735 & 13,8 & 5.336 & 100 \\
\hline 1775-79 & 605 & 11,5 & 572 & 10,8 & 3.361 & 63,8 & 734 & 13,9 & 5.272 & 98 \\
\hline $1780-84$ & 611 & 11,4 & 718 & 13,4 & 3.306 & 61,5 & 740 & 13,8 & 5.375 & 100 \\
\hline $1785-89$ & 619 & 11,6 & 687 & 12,9 & 3.303 & 61,8 & 735 & 13,8 & 5.344 & 100 \\
\hline $1790-94$ & 602 & 11,3 & 688 & 13,0 & 3.281 & 61,8 & 735 & 13,9 & 5.307 & 99 \\
\hline $1795-99$ & 603 & 11,5 & 686 & 13,1 & 3.207 & 61,3 & 735 & 14,0 & 5.232 & 98 \\
\hline $1800-04$ & 552 & 11,5 & 554 & 11,6 & 3.080 & 64,4 & 596 & 12,5 & 4.782 & 89 \\
\hline 1805-09 & 463 & 11,3 & 353 & 8,6 & 2.378 & 58,2 & 889 & 21,8 & 4.083 & 76 \\
\hline $1810-14$ & 458 & 11,5 & 349 & 8,7 & 2.806 & 70,3 & 381 & 9,5 & 3.995 & 75 \\
\hline 1815-19 & 458 & 11,6 & 350 & 8,8 & 2.771 & 70,0 & 381 & 9,6 & 3.959 & 74 \\
\hline $1820-24$ & 434 & 11,7 & 349 & 9,4 & 2.548 & 68,7 & 378 & 10,2 & 3.709 & 69 \\
\hline $1825-29$ & 447 & 11,7 & 351 & 9,2 & 2.658 & 69,3 & 378 & 9,9 & 3.834 & 72 \\
\hline $1830-34$ & 510 & 11,5 & 489 & 11,1 & 2.338 & 53,0 & 1.077 & 24,4 & 4.414 & 82 \\
\hline
\end{tabular}

Fuente: Clero, L. 10.228, AHN

TABLA 6

Composición anual de las ventas de cereal y vino de la granja de Silva y porcentajes sobre el recibo total (ferrados-litros)

\begin{tabular}{|c|c|c|c|c|c|c|c|c|c|c|c|c|}
\hline \multirow[b]{2}{*}{ Años } & \multicolumn{3}{|c|}{ Trigo } & \multicolumn{3}{|c|}{ Centeno } & \multicolumn{3}{|c|}{ Maíz } & \multicolumn{3}{|c|}{ Vino } \\
\hline & Recibo & Ventas & $\%$ & Recibo & Ventas & $\%$ & Recibo & Ventas & $\%$ & Recibo & Ventas & $\%$ \\
\hline $1730-34$ & 60 & 36 & 61,1 & 336 & 317 & 94,4 & 445 & 324 & 72,7 & 1.169 & 129 & 11,1 \\
\hline $1735-39$ & 62 & 36 & 57,4 & 337 & 305 & 90,5 & 458 & 328 & 71,6 & 1.032 & 27 & 2,6 \\
\hline $1740-44$ & 61 & 33 & 53,9 & 337 & 269 & 80,0 & 501 & 372 & 74,3 & 2.138 & 835 & 39,0 \\
\hline $1745-49$ & 57 & 31 & 53,9 & 335 & 293 & 87,4 & 439 & 323 & 73,5 & 1.901 & 687 & 36,1 \\
\hline $1780-84$ & 49 & 23 & 47,8 & 329 & 222 & 67,4 & 400 & 222 & 55,5 & 1.672 & 512 & 30,6 \\
\hline $1785-89$ & 49 & 22 & 45,7 & 327 & 226 & 68,9 & 395 & 234 & 59,3 & 1.925 & 482 & 25,0 \\
\hline $1790-94$ & 51 & 26 & 50,8 & 328 & 253 & 77,0 & 415 & 248 & 59,7 & 1.885 & 654 & 34,7 \\
\hline
\end{tabular}

Fuente: Clero, L. 10.226, AHN

TABLA 7

Composición anual de las ventas de cereal del priorato de 0 Rosal y porcentajes sobre el recibo total (ferrados)

\begin{tabular}{|c|c|c|c|c|c|c|c|c|c|c|c|c|}
\hline \multirow[b]{2}{*}{ Años } & \multicolumn{3}{|c|}{ Trigo } & \multicolumn{3}{|c|}{ Centeno } & \multicolumn{3}{|c|}{ Maíz } & \multicolumn{3}{|c|}{ Mijo } \\
\hline & Recibo & Ventas & $\%$ & Recibo & Ventas & $\%$ & Recibo & Ventas & $\%$ & Recibo & Ventas & $\%$ \\
\hline $1765-69$ & 614 & 516 & 84,1 & 686 & 575 & 83,8 & 3.319 & 3.114 & 93,8 & 734 & 612 & 83,3 \\
\hline $1770-74$ & 605 & 529 & 87,4 & 685 & 580 & 84,7 & 3.312 & 3.092 & 93,4 & 735 & 666 & 90,7 \\
\hline $1775-79$ & 605 & 426 & 70,4 & 572 & 590 & 103,3 & 3.361 & 3.162 & 94,1 & 734 & 637 & 86,8 \\
\hline $1780-84$ & 611 & 481 & 78,8 & 718 & 572 & 79,7 & 3.306 & 3.127 & 94,6 & 740 & 654 & 88,4 \\
\hline $1785-89$ & 619 & 502 & 81,0 & 687 & 590 & 86,0 & 3.303 & 3.116 & 94,4 & 735 & 671 & 91,2 \\
\hline $1790-94$ & 602 & 515 & 85,5 & 688 & 592 & 85,9 & 3.281 & 3.067 & 93,5 & 735 & 625 & 85,0 \\
\hline
\end{tabular}

Fuente: Clero, L. 10.228, AHN 
TABLA 10

Ingresos, gastos y útil del priorato de Panxón (medias anuales en reales e índices). 1730-34=100

\begin{tabular}{|c|c|c|c|c|c|c|}
\hline Años & Ingresos & Índice & Gasto & Índice & Útil & Índice \\
\hline $1720-24$ & 6.032 & 71 & 1.669 & 31 & 4.363 & 142 \\
\hline $1725-29$ & 7.208 & 85 & 2.651 & 49 & 4.557 & 148 \\
\hline $1730-34$ & 8.529 & 100 & 5.459 & 100 & 3.070 & 100 \\
\hline $1735-39$ & 10.461 & 123 & 6.950 & 127 & 3.512 & 114 \\
\hline $1740-44$ & 9.467 & 111 & 3.439 & 63 & 6.027 & 196 \\
\hline $1745-49$ & 9.206 & 108 & 2.893 & 53 & 6.313 & 206 \\
\hline $1750-54$ & 10.929 & 128 & 4.330 & 79 & 6.599 & 215 \\
\hline $1755-59$ & 8.603 & 101 & 3.515 & 64 & 5.088 & 166 \\
\hline $1760-64$ & 7.636 & 90 & 2.583 & 47 & 5.053 & 165 \\
\hline $1765-69$ & 9.562 & 112 & 2.474 & 45 & 7.088 & 231 \\
\hline $1770-74$ & 8.195 & 96 & 2.801 & 51 & 5.394 & 176 \\
\hline $1775-79$ & 8.269 & 97 & 3.300 & 60 & 4.969 & 162 \\
\hline $1780-83$ & 10.043 & 118 & 3.159 & 58 & 6.884 & 224 \\
\hline
\end{tabular}

Fuente: Clero, L. 10.147, AHN

TABLA 11

Ingresos, gastos y útil de la granja de Silva (medias anuales en reales e índices). 1730-34=100

\begin{tabular}{|c|c|c|c|c|c|c|}
\hline Años & Ingresos & Índice & Gasto & Índice & Útil & Índice \\
\hline $1720-24$ & 3.030 & 55 & 1.222 & 39 & 1.808 & 77 \\
\hline $1724-29$ & 4.315 & 79 & 1.623 & 52 & 2.692 & 115 \\
\hline $1730-34$ & 5.483 & 100 & 3.149 & 100 & 2.333 & 100 \\
\hline 1735-39 & 5.409 & 99 & 3.323 & 106 & 2.086 & 89 \\
\hline $1740-44$ & 6.065 & 111 & 2.697 & 86 & 3.368 & 144 \\
\hline $1745-49$ & 6.148 & 112 & 1.930 & 61 & 4.218 & 181 \\
\hline $1750-54$ & 6.821 & 124 & 2.213 & 70 & 4.608 & 197 \\
\hline 1755-59 & 4.313 & 79 & 2.044 & 65 & 2.269 & 97 \\
\hline $1760-61$ & 3.944 & 72 & 1.503 & 48 & 2.441 & 105 \\
\hline 1765-69 & 4.466 & 81 & 1.586 & 50 & 2.880 & 123 \\
\hline $1770-74$ & 3.925 & 72 & 2.180 & 69 & 1.745 & 75 \\
\hline 1775-79 & 3.712 & 68 & 2.022 & 64 & 1.987 & 85 \\
\hline $1780-84$ & 3.524 & 64 & 2.075 & 66 & 1.450 & 62 \\
\hline 1785-89 & 3.926 & 72 & 2.675 & 85 & 1.251 & 54 \\
\hline $1790-94$ & 5.189 & 95 & 3.060 & 97 & 2.130 & 91 \\
\hline $1795-99$ & 3.787 & 69 & 2.363 & 75 & 1.424 & 61 \\
\hline 1803-04 & 4.200 & 77 & 3.111 & 99 & 1.090 & 47 \\
\hline 1805-09 & 5.392 & 98 & 6.159 & 196 & 1.268 & 54 \\
\hline $1810-14$ & 8.222 & 150 & 4.556 & 145 & 3.666 & 157 \\
\hline $1815-19$ & 7.068 & 129 & 5.154 & 164 & 2.164 & 93 \\
\hline $1823-24$ & 6.349 & 116 & 3.786 & 120 & 2.564 & 110 \\
\hline $1825-29$ & 4.524 & 83 & 3.581 & 114 & 943 & 40 \\
\hline $1830-34$ & 4.131 & 75 & 3.598 & 114 & 533 & 23 \\
\hline
\end{tabular}

Fuente: Clero, L. 10.226, AHN 
TABLA 12

Ingresos, gastos y útil del priorato de O Rosal (medias anuales en reales e índices). 1765-69=100

\begin{tabular}{|c|c|c|c|c|c|c|}
\hline Años & Ingresos & Índice & Gasto & Índice & Útil & Índice \\
\hline $1765-69$ & 41.484 & 100 & 4.326 & 100 & 37.158 & 100 \\
\hline $1770-74$ & 42.966 & 104 & 4.929 & 114 & 38.037 & 102 \\
\hline $1775-79$ & 38.074 & 92 & 5.422 & 125 & 32.652 & 88 \\
\hline $1780-84$ & 46.143 & 111 & 4.746 & 110 & 41.397 & 111 \\
\hline $1785-89$ & 45.124 & 109 & 4.929 & 114 & 40.195 & 108 \\
\hline $1790-94$ & 50.960 & 123 & 6.750 & 156 & 44.210 & 119 \\
\hline $1795-99$ & 60.502 & 146 & 7.717 & 178 & 52.785 & 142 \\
\hline $1800-04$ & 56.177 & 135 & 11.964 & 277 & 44.213 & 119 \\
\hline 1805-09 & 57.785 & 139 & 7.399 & 171 & 50.386 & 136 \\
\hline $1810-14$ & 63.870 & 154 & 10.533 & 244 & 53.336 & 144 \\
\hline 1815-19 & 50.573 & 122 & 13.823 & 320 & 36.751 & 99 \\
\hline $1820-24$ & 39.426 & 95 & 7.486 & 173 & 31.941 & 86 \\
\hline $1825-29$ & 36.824 & 89 & 8.800 & 203 & 28.024 & 75 \\
\hline $1830-34$ & 33.258 & 80 & 6.539 & 151 & 26.720 & 72 \\
\hline
\end{tabular}

Fuente: Clero, L. 10.228, AHN

TABLA 15

Ingresos, gastos y útil del priorato de Panxón (medias anuales en reales e índices). 1730-34=100

\begin{tabular}{|c|c|c|c|c|c|c|}
\hline Años & Ingresos & Índice & Gasto & Índice & Útil & Índice \\
\hline $1720-24$ & 6.032 & 71 & 1.669 & 31 & 4.363 & 142 \\
\hline $1725-29$ & 7.208 & 85 & 2.651 & 49 & 4.557 & 148 \\
\hline $1730-34$ & 8.529 & 100 & 5.459 & 100 & 3.070 & 100 \\
\hline $1735-39$ & 10.461 & 123 & 6.950 & 127 & 3.512 & 114 \\
\hline $1740-44$ & 9.467 & 111 & 3.439 & 63 & 6.027 & 196 \\
\hline $1745-49$ & 9.206 & 108 & 2.893 & 53 & 6.313 & 206 \\
\hline $1750-54$ & 10.929 & 128 & 4.330 & 79 & 6.599 & 215 \\
\hline $1755-59$ & 8.603 & 101 & 3.515 & 64 & 5.088 & 166 \\
\hline $1760-64$ & 7.636 & 90 & 2.583 & 47 & 5.053 & 165 \\
\hline $1765-69$ & 9.562 & 112 & 2.474 & 45 & 7.088 & 231 \\
\hline $1770-74$ & 8.195 & 96 & 2.801 & 51 & 5.394 & 176 \\
\hline $1775-79$ & 8.269 & 97 & 3.300 & 60 & 4.969 & 162 \\
\hline $1780-83$ & 10.043 & 118 & 3.159 & 58 & 6.884 & 224 \\
\hline
\end{tabular}

Fuente: Clero, L. 10.147, AHN 
TABLA 16

Ingresos, gastos y útil de la granja de Silva (medias anuales en reales e índices). 1730-34=100

\begin{tabular}{|c|c|c|c|c|c|c|}
\hline Años & Ingresos & Índice & Gasto & Índice & Útil & Índice \\
\hline $1720-24$ & 3.030 & 55 & 1.222 & 39 & 1.808 & 77 \\
\hline $1724-29$ & 4.315 & 79 & 1.623 & 52 & 2.692 & 115 \\
\hline 1730-34 & 5.483 & 100 & 3.149 & 100 & 2.333 & 100 \\
\hline 1735-39 & 5.409 & 99 & 3.323 & 106 & 2.086 & 89 \\
\hline $1740-44$ & 6.065 & 111 & 2.697 & 86 & 3.368 & 144 \\
\hline $1745-49$ & 6.148 & 112 & 1.930 & 61 & 4.218 & 181 \\
\hline 1750-54 & 6.821 & 124 & 2.213 & 70 & 4.608 & 197 \\
\hline 1755-59 & 4.313 & 79 & 2.044 & 65 & 2.269 & 97 \\
\hline 1760-61 & 3.944 & 72 & 1.503 & 48 & 2.441 & 105 \\
\hline 1765-69 & 4.466 & 81 & 1.586 & 50 & 2.880 & 123 \\
\hline 1770-74 & 3.925 & 72 & 2.180 & 69 & 1.745 & 75 \\
\hline $1775-79$ & 3.712 & 68 & 2.022 & 64 & 1.987 & 85 \\
\hline $1780-84$ & 3.524 & 64 & 2.075 & 66 & 1.450 & 62 \\
\hline 1785-89 & 3.926 & 72 & 2.675 & 85 & 1.251 & 54 \\
\hline 1790-94 & 5.189 & 95 & 3.060 & 97 & 2.130 & 91 \\
\hline 1795-99 & 3.787 & 69 & 2.363 & 75 & 1.424 & 61 \\
\hline 1803-04 & 4.200 & 77 & 3.111 & 99 & 1.090 & 47 \\
\hline 1805-09 & 5.392 & 98 & 6.159 & 196 & 1.268 & 54 \\
\hline 1810-14 & 8.222 & 150 & 4.556 & 145 & 3.666 & 157 \\
\hline 1815-19 & 7.068 & 129 & 5.154 & 164 & 2.164 & 93 \\
\hline $1823-24$ & 6.349 & 116 & 3.786 & 120 & 2.564 & 110 \\
\hline $1825-29$ & 4.524 & 83 & 3.581 & 114 & 943 & 40 \\
\hline 1830-34 & 4.131 & 75 & 3.598 & 114 & 533 & 23 \\
\hline
\end{tabular}

Fuente: Clero, L. 10.226, AHN

TABLA 17

Ingresos, gastos y útil del priorato de O Rosal (medias anuales en reales e índices). 1765-69=100

\begin{tabular}{|c|c|c|c|c|c|c|}
\hline Años & Ingresos & Índice & Gasto & Índice & Útil & Índice \\
\hline $1765-69$ & 41.484 & 100 & 4.326 & 100 & 37.158 & 100 \\
\hline $1770-74$ & 42.966 & 104 & 4.929 & 114 & 38.037 & 102 \\
\hline $1775-79$ & 38.074 & 92 & 5.422 & 125 & 32.652 & 88 \\
\hline $1780-84$ & 46.143 & 111 & 4.746 & 110 & 41.397 & 111 \\
\hline $1785-89$ & 45.124 & 109 & 4.929 & 114 & 40.195 & 108 \\
\hline $1790-94$ & 50.960 & 123 & 6.750 & 156 & 44.210 & 119 \\
\hline $1795-99$ & 60.502 & 146 & 7.717 & 178 & 52.785 & 142 \\
\hline $1800-04$ & 56.177 & 135 & 11.964 & 277 & 44.213 & 119 \\
\hline $1805-09$ & 57.785 & 139 & 7.399 & 171 & 50.386 & 136 \\
\hline $1810-14$ & 63.870 & 154 & 10.533 & 244 & 53.336 & 144 \\
\hline $1815-19$ & 50.573 & 122 & 13.823 & 320 & 36.751 & 99 \\
\hline $1820-24$ & 39.426 & 95 & 7.486 & 173 & 31.941 & 86 \\
\hline $1825-29$ & 36.824 & 89 & 8.800 & 203 & 28.024 & 75 \\
\hline $1830-34$ & 33.258 & 80 & 6.539 & 151 & 26.720 & 72 \\
\hline
\end{tabular}

Fuente: Clero, L. 10.228, AHN 
GRÁFICO 1

Evolución de los índices de ingresos y útil del priorato de Panxón (1720-1783) 1730-34=100

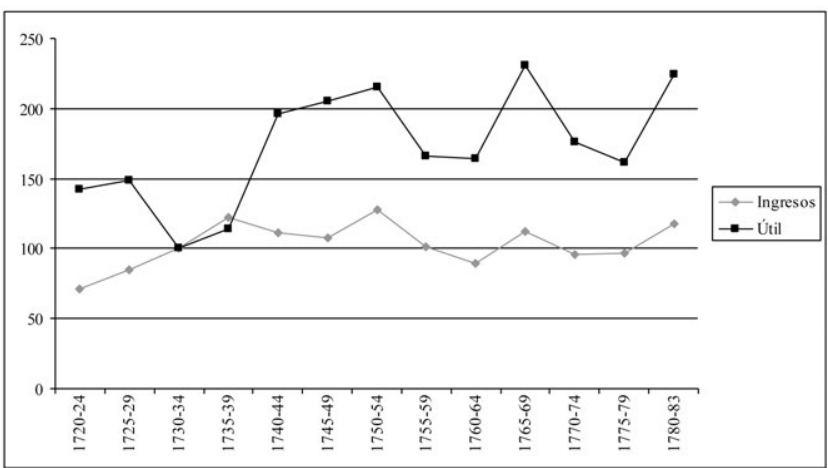

Fuente: Clero, L. 10.147, AHN

GRÁFICO 2

Evolución de los índices de ingresos y útil del priorato de Silva (1720-1834) 1730-34=100

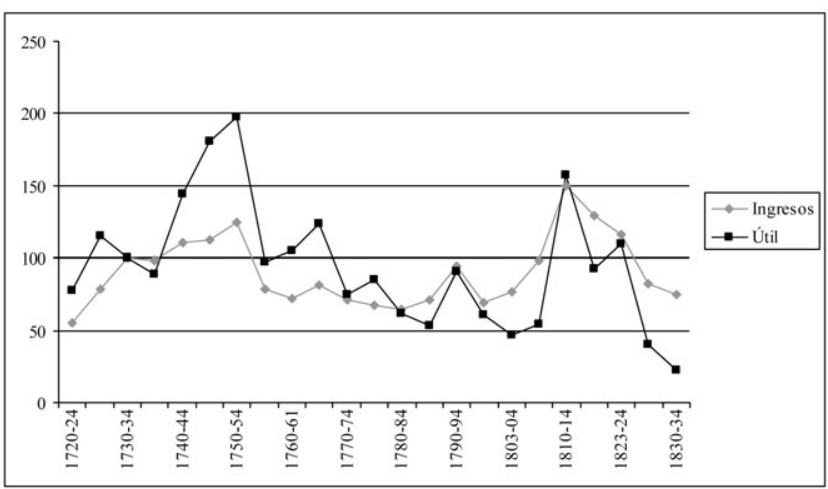

Fuente: Clero, L. 10.226, AHN

GRÁFICO 3

Evolución de los índices de ingresos y útil del priorato 0 Rosal (1765-1834) $1765-69=100$

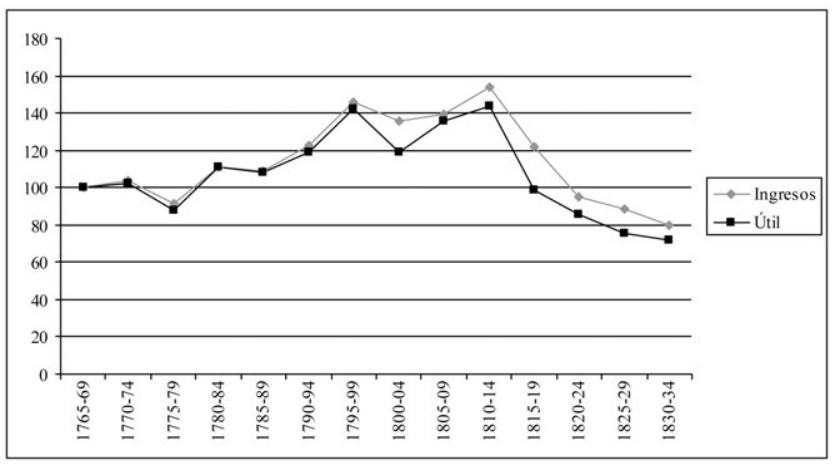

Fuente: Clero, L. 10.228, AHN
GRÁFICO 4

Estructura de los ingresos en Panxón

(1730-1780)

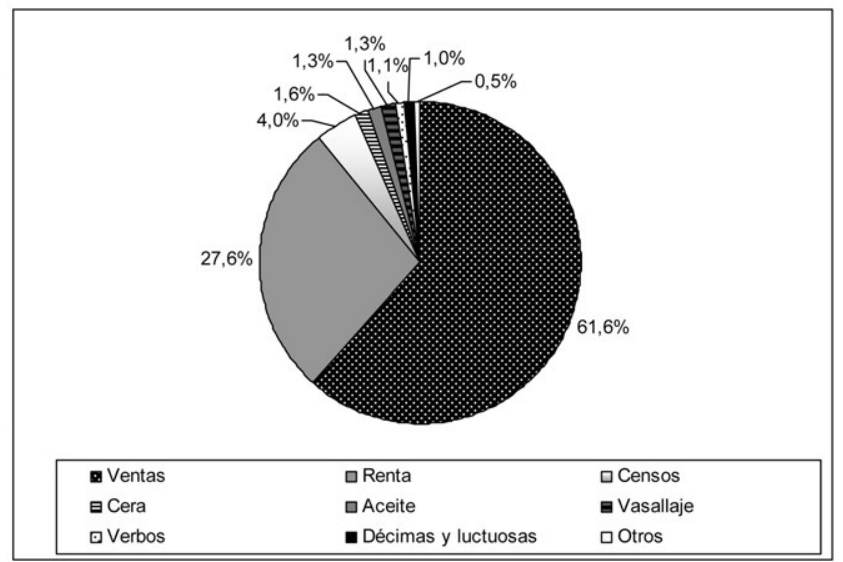

Fuente: Clero, L. 10.147, AHN

GRÁFICO 5

Estructura de los ingresos en Silva (1730-1780)

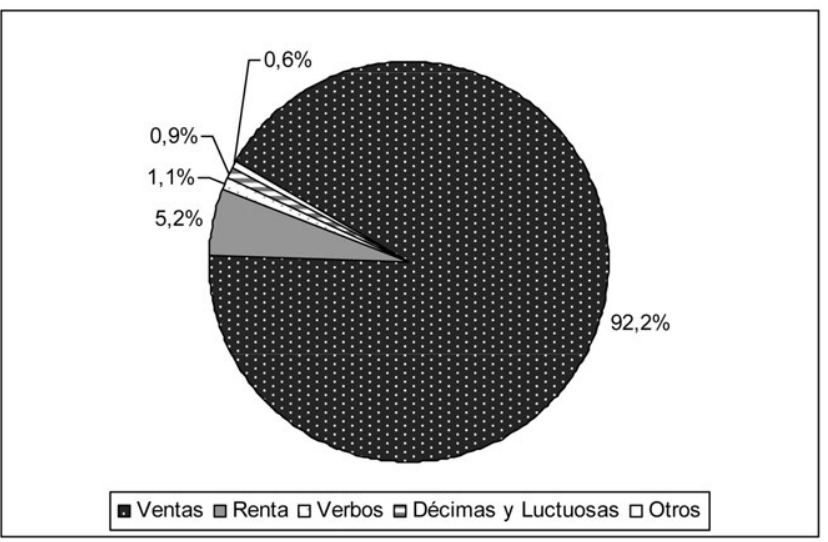

Fuente: Clero, L. 10.226, AHN 